2013

\title{
CHARACTERIZING THE FIRST HISTORIC ERUPTION OF NABRO, ERITREA: INSIGHTS FROM THERMAL AND UV REMOTE SENSING
}

Christine Ruth Sealing

Michigan Technological University

Follow this and additional works at: https://digitalcommons.mtu.edu/etds

Part of the Geology Commons, and the Remote Sensing Commons

Copyright 2013 Christine Ruth Sealing

\section{Recommended Citation}

Sealing, Christine Ruth, "CHARACTERIZING THE FIRST HISTORIC ERUPTION OF NABRO, ERITREA: INSIGHTS FROM THERMAL AND UV REMOTE SENSING", Master's Thesis, Michigan Technological University, 2013.

https://doi.org/10.37099/mtu.dc.etds/646

Follow this and additional works at: https://digitalcommons.mtu.edu/etds

Part of the Geology Commons, and the Remote Sensing Commons 
CHARACTERIZING THE FIRST HISTORIC ERUPTION OF NABRO, ERITREA: INSIGHTS FROM THERMAL AND UV REMOTE SENSING

By

Christine R. Sealing

\begin{abstract}
A THESIS
Submitted in partial fulfillment of the requirements for the degree of

MASTER OF SCIENCE

In Geology
\end{abstract}

MICHIGAN TECHNOLOGICAL UNIVERSITY

2013

(C) 2013 Christine R. Sealing 
This thesis has been approved in partial fulfillment of the requirements for the Degree of MASTER OF SCIENCE in Geology

Department of Geological and Mining Engineering and Sciences

Thesis Advisor: Simon Carn

Committee Member: $\quad$ Louisa Kramer

Committee Member: Benjamin van Wyk de Vries

Department Interim Chair: John Gierke 


\section{Contents}

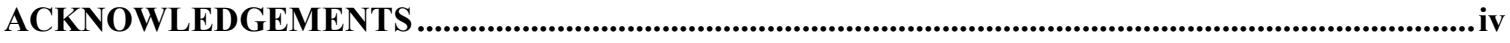



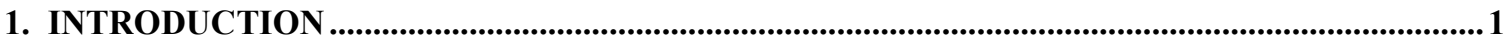

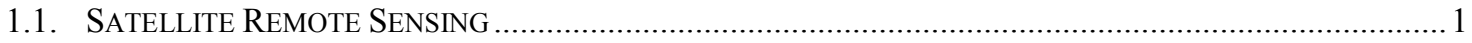

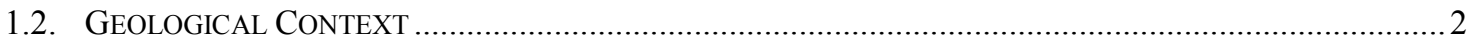

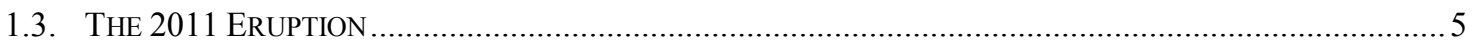

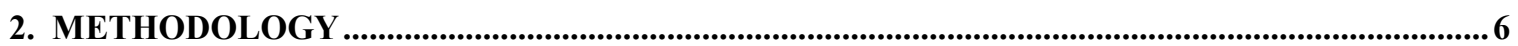

2.1. THERMAL REMOTE SENSING WITH MODIS ............................................................................ 7

2.1.1. The MODIS instrument ....................................................................................... 7

2.1.2. Data Acquisition and Selection.............................................................................. 8

2.1.3. Image Analysis and Effusion Rate Calculations - following Harris et al. 1997 ..................... 9

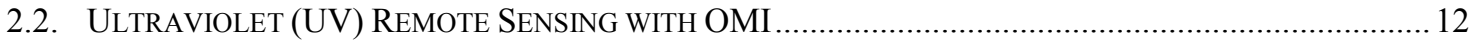

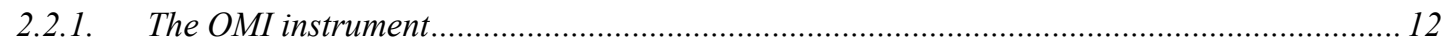

2.2.2. Calculating $\mathrm{SO}_{2}$ Mass and Flux Using OMIPLOT ................................................... 14

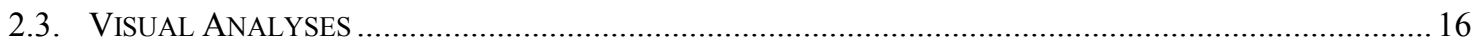

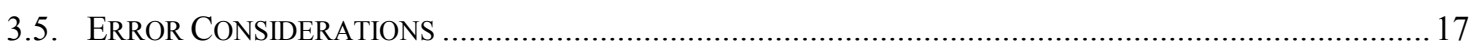

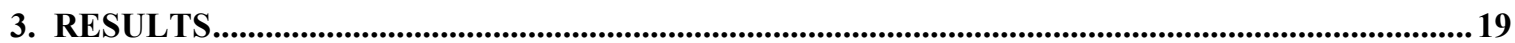

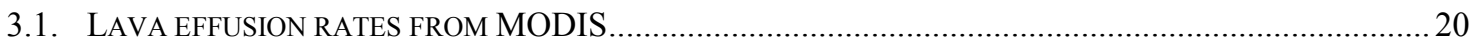

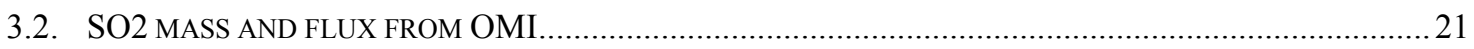

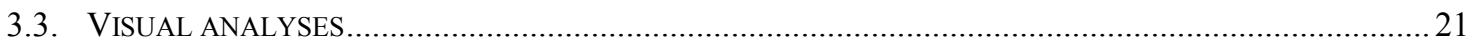

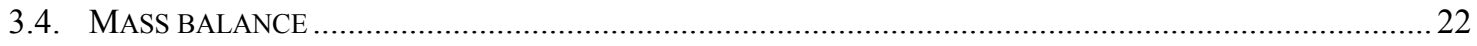

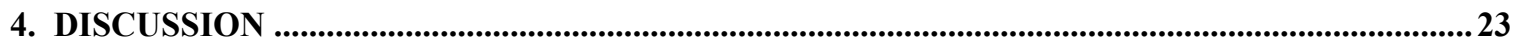

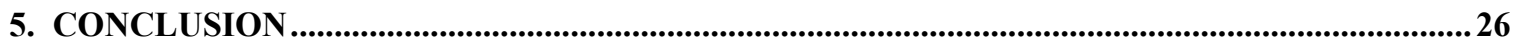

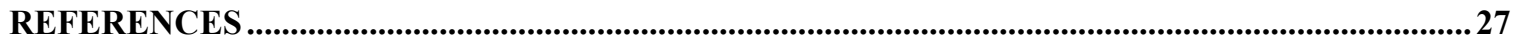





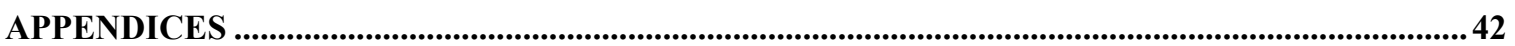




\section{ACKNOWLEDGEMENTS}

Firstly, I would like to thank my wonderful advisors, Simon and Andy, for allowing me the freedom to design this project and for their patience as I started, stalled, and blundered my way through it. Special thanks also to Riccardo Tortini, for providing more satellite data than I knew what to do with.

I would also like to acknowledge the many other great faculty at Michigan Tech and UBP, who have helped me on numerous occasions throughout my time in this program.

On a personal note, I'd like to thank all of my friends the world over, old and new, for giving me perspective and keeping me sane all the way through grad school. Special thanks to Ludo, my rock in a hard place. And to Lorenzo, who brings out my hope and happiness every day.

And of course, thank you to my Family. For my life. For everything.

This project is part of an international collaborative effort between Michigan Technological University and Université Blaise Pascal, through the INVOGE program, and as such, was made possible by a generous grant from the EU-US Atlantis Program. 


\section{ABSTRACT}

June 2011 saw the first historic eruption of Nabro volcano, one of an ongoing sequence of eruptions in the Afar-Red Sea region since 2005. It halted air travel in northern Africa, contaminated food and water sources, and displaced thousands from their homes. Due to its remote location, little was known about this event in terms of the quantity of erupted products and the timing and mechanisms of their emplacement. Geographic isolation,

previous quiescence and regional civil unrest meant that this volcano was effectively unmonitored at the time of eruption, and opportunities for field study are limited. Using free, publicly available satellite data, I examined rates of lava effusion and $\mathrm{SO}_{2}$ emission in order to quantify the amount of erupted products and understand the temporal evolution of the eruption, as well as explore what information can be gleaned about eruption mechanisms using remote sensing data. These data revealed a bimodal eruption, beginning with explosive activity marked by high $\mathrm{SO}_{2}$ emission totalling 1824 - $2299 \mathrm{KT}$, and extensive ash fall of $270-440 \mathrm{~km}^{2}$. This gave way to a period of rapid effusion, producing a $\sim 17 \mathrm{~km}$ long lava flow, and a volume of $\sim 22.1 \times 10^{6} \mathrm{~m}^{3}$. Mass balance between the $\mathrm{SO}_{2}$ and lava flows reveals no sulfur 'excess', suggesting that nearly all of the degassed magma was extruded. The 2011 eruption of Nabro lasted nearly 6 weeks, and may be considered the second largest historic eruption in Africa. Work such as this highlights the importance of satellite remote sensing for studying and monitoring volcanoes, particularly those in remote regions that may be otherwise inaccessible. 


\section{INTRODUCTION}

\subsection{Satellite Remote Sensing}

Satellite-based remote sensing is an increasingly important tool for monitoring active volcanoes. Radiant heat energy, in this case from erupted lava, is measured across the infrared (IR) spectrum by several currently-operational space-borne sensors. Similarly, sulfur dioxide $\left(\mathrm{SO}_{2}\right)$ is observed from space based on interactions in the ultraviolet (UV) and IR regions of the electromagnetic spectrum. These measurements allow us to remotely determine the type, temperature, and areal extent of lava flows, as well as the gas species present in volcanic plumes and their column abundance. These, in turn, yield valuable information about the rate and volume of lava emplacement versus gas emission. The rate at which volatile gases (such as $\mathrm{H}_{2} \mathrm{O}, \mathrm{CO}_{2}$, and $\mathrm{SO}_{2}$ ) exsolve in the magma column determines the explosivity and thus the style of an eruption. Studying lava effusion rate in conjunction with $\mathrm{SO}_{2}$ provides important insight into eruptive processes.

Wadge (1981) illustrated how eruption mechanisms can be inferred by examining the shape of lava effusion rate curves. These curves can also provide insight into the geometry of the conduit during an eruption (Wadge, 1981). The dynamics of $\mathrm{SO}_{2}$ emission and lava effusion can reveal information about the mass balance of magma (Allard et al., 1994, Carn and Prata, 2010, Denlinger, 1997, Dvorak and Dzurisin, 1993, Harris et al., 2000, Wallace, 2001) and its supply rate and movement within the volcanic system (Edmonds et al., 2010, Harris et al., 1997, Harris et al., 2000, Harris and Stevenson, 1997, Lautze et al., 2004, Oppenheimer et al., 2004). Changes in gas concentrations and lava effusion can also help shed light on magma source depth (Denlinger, 1997, Dvorak and Dzurisin, 1993, Ripepe et al., 2005). These trends can be used not only to characterize the long-term behavior of a volcano (Harris et al., 2011, Wadge, 1981, Wadge et al., 1975), but also to assess short-term activity (Harris et al., 2000, Wadge, 1981) - i.e. is this eruption episodic in nature? Is it waxing or waning? Is this a simple draining of the magma chamber, or a recharge of magma from depth? As 
effusion rate, velocity, and volume are important input parameters for lava flow models (Harris and Rowland, 2001, Rowland et al., 2005, Wadge et al., 1994, Young and Wadge, 1990), rapid, timely effusion rate calculations are also valuable for hazard mitigation. Similarly, $\mathrm{SO}_{2}$ in volcanic plumes can be tracked to study atmospheric transport mechanisms and provide crucial information for aviation hazard mitigation (Carn et al., 2008). The ability to measure these parameters in a safe and timely manner, therefore, makes satellite remote sensing an increasingly effective and powerful tool for studying active volcanoes. This can be especially important for remote volcanoes, which for physical and/or social reasons are often inaccessible.

Most of the world's volcanoes are either under-monitored or not monitored at all. This is due to a range of factors including location, cost, civil/political circumstances, and the sheer quantity of volcanoes on Earth. A recent study by Sparks et al. (2012) of volcanoes in 16 countries found that out of 439 volcanoes fewer than $13 \%$ were being effectively monitored despite the large populations at risk. Satellite remote sensing can be used to fill some of these monitoring gaps. For this reason, it is important to understand the capabilities and limitations of studying volcanoes by satellite, particularly when there is no other ground information available. To this end, this study aims to characterize the 2011 eruption of Nabro, Eritrea using free, publicly available satellite remote sensing data alone. Here, I will quantify rates and volumes of lava effusion and $\mathrm{SO}_{2}$ emission, as well as examine the temporal evolution of the eruption.

\subsection{Geological Context}

Nabro stratovolcano (Figure 1) is located within the Afar Triangle, which forms the junction between the Arabian, African and Somalian plates, west of the Gulf of Aden, at the southern end of the Red Sea. This region is characterized by extensional tectonics, active rifting, and the presence of a broad mantle plume (Schilling, 1973). The primary structural trend in the northern Afar region is NW-SE, delineated by several basaltic, axial volcanic ranges, including the oft-studied Erta Ale range. Running almost perpendicular to the primary trend are several smaller ranges with compositions 
transitioning from basaltic through rhyolitic. These ranges have been classified as marginal or transverse (Barberi et al., 1974, Barberi et al., 1970, Barberi et al., 1971, Barberi and Varet, 1977), and equated to development of pre-rift structures into Atlanticstyle transverse weak zones (Barberi et al., 1974).

Among these, the Nabro Volcanic Range (NVR), situated at the southern end of the Danakil metamorphic block, saw the two largest known historical eruptions in the Afar: the 1861 eruption of Dubbi (Wiart and Oppenheimer, 2000), and the 2011 eruption of Nabro. This predominantly silicic range has a length of $110 \mathrm{~km}$ that trends $026^{\circ}$ (Wiart and Oppenheimer, 2004), crossing the Red Sea coast roughly $120 \mathrm{~km} \mathrm{NW}$ of the port city of Assab, Eritrea. It is comprised of seven main volcanic centers that vary systematically in composition, moving from basaltic on the outer margins of the NVR, to progressively more silicic volcanism toward the centre of the range. This variation has been attributed to differences in the nature of the basement beneath the NVR (Wiart and Oppenheimer, 2004), as the centre of the range crosses the southern tip of the Danakil Alps. It is thought that the influence of continental crust in this area would likely promote longlived magma chambers, allowing for advanced magma differentiation.

Toward the centre of the range, $5 \mathrm{~km}$ from the Ethiopian border, Nabro is the highest peak in the NVR, at $2248 \mathrm{~m}$ above sea level. The summit of Nabro is capped by a distinctive horseshoe-shaped caldera, $\sim 8 \mathrm{~km}$ wide, which is open to the southwest. The main caldera houses a young volcanic centre, including two nested collapse craters, the larger of which also breaches to the southwest. Opposite Nabro, across the Ethiopian border, Mallahle rises to 1800 meters with a smaller caldera that breaches to the northeast. These two volcanoes are thought to have evolved more-or-less contemporaneously, as one large double caldera complex (Wiart and Oppenheimer, 2004). Both are characterized by trachyte and rhyolite lava flows and large sheets of ignimbrite that extend $\sim 30 \mathrm{~km}$ either side of the complex. Although both Nabro and Mallahle are largely silicic in composition, the most recent eruptions prior to 2011 consisted of basaltic lava flows greater than $20 \mathrm{~km}$ in length. These appear to have originated from vents and fissures located between the two volcanoes, trending perpendicular to the range axis and in line 
with several structural alignments that have been suggested across the NVR (Wiart and Oppenheimer, 2004).

Since 2005, the northern region of the Afar Triangle has entered a dramatic phase of active rifting, including numerous dyke intrusions and a marked increase in eruptive activity (Ferguson et al., 2010, Keir et al., 2009). Until recently, the volcanism associated with this new phase of rifting has occurred only in the Erta Ale and DabbahuManda Hararo axial ranges and the Red Sea (Table 1). Each of these eruptive episodes has been relatively small and short lived, characterized by moderate gas emissions and lava emplacement by fissure fountains (Ferguson et al., 2010, Grandin et al., 2009, Keir et al., 2009, Pagli et al., 2012, Rowland et al., 2007, Wright et al., 2006). In contrast, the recent eruption of Nabro was significantly greater in magnitude, and emanated from a nested crater inside the summit caldera, as opposed to flank fissure vents. Its location is markedly different, being situated in a marginal instead of axial range, and it produced the highest eruption plume seen in the Afar region for 150 years.

Although the initial injection height of the volcanic plume is hotly debated ((Bourassa et al., 2012, Bourassa et al., 2013, Fromm et al., 2013, Vernier et al., 2013); described below), it is agreed that $\mathrm{SO}_{2}$ from Nabro did reach stratospheric altitudes within the first days of the eruption. When large concentrations of $\mathrm{SO}_{2}$ reach the stratosphere, these molecules oxidize into sulfuric acid droplets, increasing the stratospheric aerosol load. This is significant, as it suggests that Afar volcanoes may have the potential to produce eruptions large enough to affect climate. This has already been postulated for the 1861 eruption of Dubbi, which coincided with an anomalously cold Northern Hemisphere summer the following year (Wiart and Oppenheimer, 2000).

The Dubbi eruption produced $1.2-3.5 \mathrm{~km}^{3}$ of hawaiite lava (Wiart and Oppenheimer, 2000, Wiart et al., 2000) and trachytic pumice covering a minimum of $70 \mathrm{~km}^{2}$ (Wiart et al., 2000). Pyroclastic flows from this eruption resulted in loss of life and livelihood from surrounding villages, and heavy ash fall disrupted maritime traffic in the Red Sea. With the creation of the Suez canal, the southern end of the Red Sea has become a major 
commercial route, affording passage to and from the Mediterranean. Large explosive eruptions, like the one from Dubbi, could wreak havoc on this economically important maritime thoroughfare. Similarly, the impact to aviation would be quite significant from an eruption of this size, particularly if ash was caught up in the stratosphere and transported across the Middle East and Asia by the monsoon winds.

As the rifting cycle progresses and new magma is supplied from depth, the northern Afar is likely to see more frequent eruptions of possibly greater magnitude (Ferguson et al., 2010). As the eruption at Nabro suggests, the location of future eruptions will be difficult to predict and may easily occur at historically unmonitored volcanoes. For this reason, it is important to identify gaps in our monitoring capabilities and glean as much information as possible from this area remotely.

\subsection{The 2011 Eruption}

13 June 2011 saw the first documented historical eruption of Nabro volcano, which was characterized in the beginning by thick ash plumes followed by scoria and extensive basalt effusion. The evening prior to the eruption, the United States Geological Survey (USGS) reported a total of 14 earthquakes ranging from M 4.5 - M 5.7, originating near the Eritrea-Ethiopia border, $128 \mathrm{~km} \mathrm{WNW}$ of Assab (Smithsonian, 2011). According to reports from the Toulouse Volcanic Ash Advisory Centre (VAAC), the eruption at Nabro began sometime between 0300-0500 local time on 13 June, with an eruption plume that rose up to $13.7 \mathrm{~km}$ a.s.1., eventually drifting over $1000 \mathrm{~km} \mathrm{NW}$ to Sudan (Smithsonian, 2011). This initial plume height estimate reported by the Toulouse VAAC became the subject of some controversy when Bourassa et al. (2012) used it to argue that the high stratospheric aerosol content resulted from transport via deep monsoon convection. In

comments to that work, however, Vernier et al. (2013) and Fromm et al. (2013) provided satellite evidence that the 13 June eruption plume reached altitudes of 15 to $19 \mathrm{~km}$, allowing injection of $\mathrm{SO}_{2}$ directly into the stratosphere. According to Bourassa et al. (2012), this eruption resulted in the largest stratospheric aerosol abundance since the eruption of Mount Pinatubo. 
The eruption continued for at least 40 days, producing expansive $\mathrm{SO}_{2}$ plumes and a large basalt lava flow over $17 \mathrm{~km}$ in length. The Eritrean Ministry of Information reported ash fall covering hundreds of kilometers (Smithsonian, 2011). According to the Smithsonian (2011), there were a total of 7 deaths and numerous injuries recorded during this eruption. Over the following weeks, airlines cancelled flights, ash fall contaminated food and water sources, and thousands of people evacuated from their homes. One year later, Nabro was still producing significant heat from its summit caldera, suggesting continued activity during that time, possibly in the form of small lava flows or a circulating lava lake.

Relatively little was known about Nabro prior to the 2011 eruption. Political instabilities in the region make access to the volcano extremely difficult. These access difficulties coupled with the absence of historical eruptions meant that Nabro was effectively unmonitored by ground instruments at the time of the eruption. Satellite remote sensing, therefore, remains the primary technique for studying this eruption, and a critical tool for monitoring future eruptions at Nabro.

\section{METHODOLOGY}

Exsolution of volatile gases (e.g. $\mathrm{SO}_{2}, \mathrm{CO}_{2}$, and $\mathrm{H}_{2} \mathrm{O}$ ) is the primary mechanism for driving magma to the surface. The rate of volatile exsolution determines the style of eruption, so that rapid exsolution results in magma fragmentation leading to explosive eruptions. Conversely, slower exsolution of volatiles produces more effusive-style eruptions. $\quad \mathrm{SO}_{2}$ is one of the most abundant volcanic gases, yet its background concentration in the atmosphere is very low. This fact in combination with a distinctive spectral signature in the UV and thermal IR wavelengths makes $\mathrm{SO}_{2}$ easily measureable from remote spectroscopic methods, and thus ideal for studying volcanic behavior from satellite. Examining the rate (or flux) of $\mathrm{SO}_{2}$ emission and lava effusion can provide important insight into the dynamics of magma supply and movement within the conduit. Comparing the mass of $\mathrm{SO}_{2}$ versus that of erupted lava can also give insight into the sulfur content of the melt and the mass balance of the system. These parameters, $\mathrm{SO}_{2}$ and 
lava effusion, can be measured near-simultaneously from instruments aboard the Aqua and Aura satellites in the international Afternoon Train (A-Train) constellation. In this study, I derive lava effusion rates and $\mathrm{SO}_{2}$ mass and flux for the 2011 eruption of Nabro from thermal IR and UV satellite instruments, respectively. I then use this to infer conduit dynamics and piece together a timeline this eruption.

\subsection{Thermal Remote Sensing with MODIS}

\subsubsection{The MODIS instrument}

The Moderate Resolution Imaging Spectroradiometer (MODIS), built and operated by the National Aeronautics and Space Administration (NASA), is the cornerstone instrument on board the Terra (AM-1) and Aqua (PM-1) platforms. Launched in 1999 and 2002 respectively, as part of the NASA Earth Observing System (EOS), Terra and Aqua are sun-synchronous, near-polar orbiting satellites that operate at an altitude of 705 kilometers above the surface.

MODIS is a passive, multispectral instrument, with 490 detectors arranged in 36 spectral bands across the visible and infrared spectrum. Spatial resolution varies from 250 meters for bands 1 - 2 (visible bands) to 500 meters for bands 3 - 7 (visible and near-infrared (NIR)) to 1000 meters for the remaining bands (visible to thermal infrared (TIR)). The instrument's cross-track scanner subtends an angle of $110^{\circ}$ (or $\pm 55^{\circ}$ either side of nadir). With a swath width of $2330 \mathrm{~km}$ across track and $10 \mathrm{~km}$ along track, each instrument achieves global coverage every 1-2 days. This excellent compromise of spatial and temporal resolution makes MODIS a powerful tool for studying the Earth system. The spectral, spatial and temporal characteristics of the MODIS instrument are listed in Appendix A. Data from this instrument can be accessed by the public at no cost via the NASA MODIS webpage (http://modis.gsfc.nasa.gov/data/). 


\subsubsection{Data Acquisition and Selection}

In order to constrain the temporal breadth of this study, I first examined images and Alert Files from the MODVOLC near-real-time thermal monitoring system, operated by the Hawaii Institute of Geophysics and Planetology (Wright et al., 2002, Wright et al., 2004). The MODVOLC algorithm scans the MODIS Level 1B data stream for evidence of pixel and sub-pixel thermal anomalies for the purpose of detecting eruptive activity in nearreal-time. The detection threshold of the algorithm is set to maximize hotspot detection while minimizing the occurrence of "false positives" as much as possible. However, it is impossible to obtain $100 \%$ accuracy. Thus, other high-temperature radiators such as brush fires may be detected while weak volcanic hotspots may be missed by the algorithm. For 12 months prior to the eruption, there were no hotspots detected on or around Nabro. MODVOLC data suggest that the bulk of the eruption occurred between 13 June and 25 July 2011; therefore, I chose these dates to bracket the MODIS study period.

Each MODIS instrument acquires 2-3 images per 24 hours over Nabro (Figure 2). Using the NASA Level 1 and Atmosphere Archive and Distribution System, I obtained both day and night images for the duration of the study period; however, adverse atmospheric conditions and edge effects often meant that only 1 image per instrument per day was useable. Out of 225 images acquired, 57 were useable for this study. Appendix B gives a graphical representation of the quantity and attributes of images examined in this study.

For each image, I examined spectral bands 21 (3.929 - $3.989 \mu \mathrm{m}$, middle infrared (MIR)) and 32 (11.770 - $12.270 \mu \mathrm{m}$, TIR) separately, using ENVI 4.8 (Environment for Visualizing Images) software. Small, high-temperature radiators such as cracks in the crusted lava flow tend to dominate the signal at shorter wavelengths, producing unrealistic effusion rates (Harris, 2013, Harris and Baloga, 2009); therefore, I used band 21 for reference only, and calculated lava effusion rates from band 32 following the method of Harris et al. (1997), described below. In the case of saturated pixels, I 
assumed the known saturation temperature for band 32 of $420 \mathrm{~K}$ (Wright et al., 2002), expecting the result to represent a minimum effusion rate for those images.

\subsubsection{Image Analysis and Effusion Rate Calculations - following Harris et al. 1997}

Given the MODIS spatial resolution of $1 \mathrm{~km}^{2}$ at nadir, it is safe to assume that any anomalous (hot spot) pixels will be "mixed", that is containing both hot active lava and cold ground surface temperatures. As lava flow area is the main variable governing effusion rate calculations from space (Wright et al., 2001), we must determine the area of active lava contained within each anomalous pixel. To do this, we compare the radiance of each hot spot pixel to that of its least radiant neighboring background pixel. The procedure is laid out in the subsections below.

\section{A note on timing:}

This report follows the terminology of Harris et al. (2007) for lava effusion rate terms involving a time component, specifically instantaneous effusion rate, eruption rate, and time-averaged discharge rate (TADR). Here, the instantaneous effusion rate is the volume flux of lava reaching the surface at any given point in time. TADR is defined as the average effusion rate over a specific window of time. This should not be confused with the eruption rate, which is the mean effusion rate from the beginning of the eruption until a designated point in time. As satellite images represent isolated windows in time, this study examines predominately effusion rate curves derived from measurements of TADR.

\subsubsection{Atmospheric Corrections}

From Harris et al. (1997), the radiance arriving at the sensor $\left(R_{t o t}\right)$ is a combination of the radiance from the surface $\left(R_{s}\right)$, the surface emissivity at a given wavelength $\left(\varepsilon_{\lambda}\right)$, and several atmospheric components. In order to estimate lava area and effusion rate, we much first remove these other components to leave only the surface radiance, given by the equation 


$$
R_{s}=\frac{R_{t o t}-R_{u p}-R_{r e f}}{\tau_{\lambda} \varepsilon_{\lambda}}
$$

where $R_{u p}$ is the upwelling atmospheric path radiance, $R_{r e f}$ is the reflected atmospheric radiance, and $\tau_{\lambda}$ is the atmospheric transmissivity at a given wavelength. Assuming a standard atmosphere, I used MODTRAN (ref) to estimate $\tau_{\lambda}$ and $R_{u p}$, taking into account scan angle and pixel elevation for each image. For band 32 in the thermal infrared, $R_{r e f}$ is negligible; however, $R_{r e f}$ can contribute significantly to the radiance at lower wavelengths. Arid regions such as Afar contain less atmospheric water vapor than average conditions elsewhere. This would reduce the path radiance and increase atmospheric transmission in this region. Thus, the assumption of a standard atmosphere may not strictly apply. The emissivity value was chosen based on literature (Table 2).

\subsubsection{Estimating Lava Flow Area}

We begin by finding the brightness temperature of each anomalous pixel and its associated background pixel by inverting the Planck Function. The Planck Function describes the relationship of spectral radiance $\left(R_{(\lambda, T)}\right.$; in $\left.\mathrm{W} \mathrm{m}^{-2} \mathrm{~m}^{-1}\right)$ to temperature $(T$; in Kelvin) and wavelength ( $\lambda$; in $\mathrm{m})$ :

$$
R_{(\lambda, T)}=2 h c^{2} \lambda^{-5}\left(e^{\frac{h c}{\lambda k T}}-1\right)^{-1}
$$

where $h$ is the Planck constant, $c$ is the speed of light, and $k$ is the Boltzmann gas constant. Combining the constants and rearranging yields the inverse Planck Function from which we can derive the brightness temperature of each pixel:

$$
T=\frac{c_{2}}{\lambda \ln \left(\frac{c_{1}}{R_{(\lambda, T)} \lambda^{5}}+1\right)}
$$

where $c_{1}=2 \pi h c^{2}$ and $c_{2}=h c / k$.

Now we determine the area of hot active lava contained in each anomalous pixel by comparing it to its associated background pixel. If the spectral radiance of each 
anomalous pixel $\left(R_{(\lambda, T a)}\right)$ is assumed to be due to radiance from a combination of hot areas (lava) and cold areas (ambient ground temperature), then

$$
R_{(\lambda, T a)}=p L_{(\lambda, T h)}+(1-p) R_{(\lambda, T b)}
$$

where $R_{(\lambda, T b)}$ is the measured radiance of the chosen background pixel (cold), $L_{(\lambda, T h)}$ is the radiance of the active lava (hot), and $p$ is the pixel fraction occupied by hot active lava. As $L_{(\lambda, T h)}$ and $p$ are both unknown, one of these variables will be assumed. Here, we assume an average temperature over the whole lava flow, then use the Planck Function (equation 1.1) to find a radiance value for $L_{(\lambda, T h)}$. Rearranging this equation, we can then determine the fraction of the pixel occupied by active lava,

$$
p=\frac{R_{\left(\lambda, T_{a}\right)}-R_{(\lambda, T b)}}{L_{\left(\lambda, T_{h}\right)}-R_{(\lambda, T b)}}
$$

which can then be used to find the area of active lava within the anomalous pixel. Summing the areas of active lava for each pixel will then yield the area of active lava over the whole of the hot spot, for each image.

\subsubsection{Thermal Flux and Instantaneous Effusion Rate}

The total surface heat loss $\left(Q_{t o t}\right)$ from an active flow field can be described as the radiant heat flux $\left(Q_{r a d}\right)$ plus the heat lost by convection $\left(Q_{c o n v}\right)$, so that

$$
Q_{t o t}=Q_{r a d}+Q_{c o n v}
$$

Radiant heat flux $\left(Q_{r a d}\right)$ is calculated using a modified version of the Stefan-Boltzmann equation, such that

$$
Q_{\text {rad }}=8 \sigma A T^{4}
$$

where $\varepsilon$ is the emissivity of the lava, $\sigma$ is the Stefan-Boltzmann constant, $A$ is the area of active lava, and $T$ is the temperature used to model the lava radiance $L_{(\lambda, T h)}$ in equation 4 , above. 
Convective heat flux $\left(Q_{\text {conv }}\right)$ is also calculated using the lava flow area $(A)$ as well as the convective heat transfer coefficient $\left(h_{c}\right)$, so that

$$
Q_{\text {conv }}=A h_{c}\left(T-T_{a}\right)
$$

where $T$ is the temperature as above, and $T_{a}$ is the ambient air temperature. Summing $Q_{r a d}$ and $Q_{c o n v}$ gives us $Q_{t o t}$, which we can then use to calculate the instantaneous effusion rate.

Based on the work of Pieri and Baloga (1986), we know that the instantaneous effusion rate $\left(E_{r}\right)$ can be expressed as

$$
E_{r}=\frac{Q_{t o t}}{\rho\left(C_{p} \Delta T+\phi C_{L}\right)}
$$

where $\rho$ is the lava density, $C_{p}$ is specific heat capacity, and $\Delta T$ is the temperature change from initial effusion to the cessation of forward movement (i.e. the temperature of the lava when it first reaches the surface, minus the temperature at which the flow stops moving). The second term inside the parentheses is the average mass fraction of crystals ( $\phi)$ multiplied by the latent heat of crystallization $\left(C_{L}\right)$. These and other assumed values are listed with references in Table 2. Finally, integrating $E_{r}$ over time then yields approximate lava flow volumes for each episode of the eruption. The calculations for lava flow area and effusion rate rely heavily on an assumption of temperature. To overcome this, I have calculated separate effusion rate curves and volumes based on a range of three temperatures $\left(100,350\right.$, and $\left.600{ }^{\circ} \mathrm{C}\right)$. Section 3.1 contains the results of these calculations.

\subsection{Ultraviolet (UV) Remote Sensing with OMI}

\subsubsection{The OMI instrument}

The Ozone Monitoring Instrument (OMI) is carried on board the EOS Aura satellite, a sun-synchronous, near-polar orbiting spacecraft which, like Aqua, is part of the international A-Train constellation. Launched in 2004, the instrument itself is a result of 
collaboration between the Netherlands's Agency for Aerospace Programs (NIVR) and the Finnish Meteorological Institute (FMI).

The OMI sensor measures a number of trace gases in the atmosphere, including $\mathrm{O}_{3}, \mathrm{NO}_{2}$, $\mathrm{BrO}, \mathrm{HCHO}, \mathrm{OClO}$, and $\mathrm{SO}_{2}$ (the focus of this study), as well as cloud pressures, aerosols, and UV surface irradiance (Levelt et al., 2006). This instrument employs a wide-field telescope to direct solar back-scattered radiation to two independent spectrometers, each with a 2-D charge couple device (CCD) detector. These spectrometers measure radiation between 350 - $500 \mathrm{~nm}$ (VIS), 270 - $314 \mathrm{~nm}$ (UV-1), and 306 - $380 \mathrm{~nm}$ (UV-2). This overlap makes OMI a hyperspectral instrument, covering a wide range of visible and UV wavelengths. The sensor's pushbroom arrangement means that these measurements are taken instantaneously across the full $2600 \mathrm{~km}$ swath. The instrument has a spatial resolution of $13 \times 24 \mathrm{~km}$ (VIS and UV-2) at nadir (the highest ever for a UV satellite instrument), and daily global coverage at low latitudes. A table of instrument specifications can be found in Appendix A. As with MODIS, OMI data can be obtained by the public free of charge via internet from the NASA Goddard Earth Sciences Data and Information Services Center (http://disc.sci.gsfc.nasa.gov/Aura/dataholdings/OMI).

OMI retrieves $\mathrm{SO}_{2}$ column amounts in Dobson Units (DU). Early $\mathrm{OMI} \mathrm{SO}_{2}$ retrievals utilized the band residual difference (BRD) algorithm developed by Krotkov et al. (2006), which takes advantage of differential $\mathrm{SO}_{2}$ absorption at four discrete $\mathrm{UV}$ wavelengths, between 310.8 and $314.4 \mathrm{~nm}$. This approach is highly sensitive to low $\mathrm{SO}_{2}$ column amounts, however the band residual differences are non-linear at column amounts above approximately 20 DU (Yang et al., 2007), making it unsuitable for large $\mathrm{SO}_{2}$ loadings. To address this issue, Yang et al. (2007) developed the Linear Fit (LF) algorithm based on an older spectral fitting technique developed for the Solar Backscattered Ultraviolet (SBUV) instrument. This newer algorithm uses a flexible range of UV bands for simultaneous retrieval of vertical $\mathrm{SO}_{2}$ columns, surface reflectivity, and ozone, and has greatly expanded the range of measurable $\mathrm{SO}_{2}$ column amounts. Assumptions of altitude are critical for this technique, as over-estimating the plume height can result in a drastic 
underestimate in $\mathrm{SO}_{2}$ column amounts and vice versa. The LF algorithm calculates $\mathrm{SO}_{2}$ column amounts for a range of four altitudes: the planetary boundary layer (PBL), lower troposphere (TRL), middle troposphere (TRM), and lower stratosphere (STL), with center of mass altitudes of $0.9,2.5,7.5$, and $17 \mathrm{~km}$, respectively. In avoiding iterative processes, the LF algorithm still underestimates column amounts for very high $\mathrm{SO}_{2}$ loadings ( $>100$ DU; (Yang et al., 2007)), however it is much faster than more computationally heavy algorithms, making the LF technique better for near-real-time monitoring.

Since June 2007, the OMI instrument has been experiencing a dynamic row anomaly, corresponding to rows on the CCD detectors, which affects the quality of Level 1B data at all wavelengths for a particular view direction. This renders wide swaths of data unusable. Due to the row anomaly and the underestimation of column amounts at high SO2 loadings by the LF algorithm, the results of $\mathrm{SO}_{2}$ mass and flux calculations using OMI data could be considered minimum values.

\subsubsection{Calculating $\mathrm{SO}_{2}$ Mass and Flux Using OMIPLOT}

For this portion of the study, I used the publicly available OMI Level 2 OMSO2 data product which had been obtained previously via the NASA Mirador website (http://mirador.gsfc.nasa.gov/). Prior to processing, I first examined archived images from NASA's Global Sulfur Dioxide Monitoring website (http://so2.gsfc.nasa.gov/), in order to determine the start and end dates of $\mathrm{SO}_{2}$ release for this eruption. These dates, 13 June - 26 July 2011, overlap well with the main period of lava effusion, described above, as constrained by MODVOLC. Appendix B: gives an indication of data availability during this time.

From here, I used the OMIplot software package (Simon Carn (2011), "OMIplot," https://vhub.org/resources/682) to visualize $\mathrm{SO}_{2}$ column amounts, cloud fraction and aerosol data, and to analyze these data for $\mathrm{SO}_{2}$ mass and flux. OMIplot is written in the Interactive Data Language (IDL) and runs from the Linux command terminal. The OMI 
instrument images Nabro once per day. Using OMIplot, I analyzed each day of the study period separately. Data were unfiltered, and I chose the LF algorithm, described above, for $\mathrm{SO}_{2}$ column retrieval. After defining coordinate boundaries for the area of interest around Nabro, I chose Mercator projection for the maps, and set display scales for $\mathrm{SO}_{2}$ and aerosols at 0 to $20 \mathrm{DU}$ and -2 to 2, respectively. Based on these user inputs, OMIplot displays $\mathrm{SO}_{2}$ retrievals for the four altitudes described above (PBL, TRL, TRM, and STL), as well as cloud fraction (CF) and aerosol index (AI) (Figure 3).

As mentioned above, in order to quantify $\mathrm{SO}_{2}$ column amounts (and hence $\mathrm{SO}_{2}$ loading) from satellite data, it is necessary to know or assume the altitude of the plume. Additionally, to quantify $\mathrm{SO}_{2}$ flux it is also necessary to know the speed of the plume, corresponding to the wind speed at plume altitude. I used the Hybrid Single Particle Lagrangian Integrated Trajectory (HYSPLIT) model, accessible through the National Oceanic and Atmospheric Administration (NOAA) Air Resources Laboratory (Draxler, 1999, Draxler and Hess, 1997, Draxler and Hess, 1998, Draxler and Rolph, 2013, Rolph, 2013), to constrain these two important parameters. HYSPLIT uses archived meteorological data to compute the advection or simple trajectory of a single particle. After inputting the time, starting location, and the altitudes of interest, HYSPLIT outputs a 2-D plan view map showing the wind trajectories at each altitude (Figure 4). I estimated the plume height for each OMI image by running the forward trajectory model for multiple altitudes, and matching the observed plume direction with the model. I then calculated the wind speed based on the chosen trajectory. I did examine other methods for constraining plume height, such as the Atmospheric Infrared Sounder (AIRS), on the Aqua platform, and the Cloud-Aerosol Lidar with Orthogonal Polarization (CALIOP) instrument, on the NASA CALIPSO platform. While the AIRS images were useful in some instances, both high dust loadings and meteorological clouds interfered with plume detection rendering the CALIOP profiles inconclusive.

To calculate the $\mathrm{SO}_{2}$ mass in the plume using OMIplot, the user must define the plume and background areas using the polygon drawing tool. Although defining the plume is fairly straightforward, the representative background should be chosen in an area that is 
free of $\mathrm{SO}_{2}$, aerosols, and meteorological cloud, whenever possible. Once these areas are defined, OMIplot subtracts the normalized background $\mathrm{SO}_{2}$ loading from the volcanic plume $\mathrm{SO}_{2}$ loading, generating mass and column amounts (in tons and DU, respectively) for each of the four altitude windows. The user must chose which altitude is appropriate based on an estimate of plume height, in this case using the HYSPLIT forward trajectory model described above.

To calculate $\mathrm{SO}_{2}$ flux, the user must transect the plume perpendicular to the dominant wind direction (i.e. perpendicular to the direction of the plume) to obtain a plume crosssection, then enter the wind speed when prompted. The software then calculates $\mathrm{SO}_{2}$ flux as the product of the integrated plume cross-section and the wind speed (assumed to represent plume speed), and outputs the results (in tons per day) for each altitude in text form. This method is analogous to that used in many ground-based $\mathrm{SO}_{2}$ monitoring techniques. Although OMI acquires only one image per day, in this way it is possible to glean multiple flux measurements from a single image (Carn and Bluth, 2003). By drawing multiple transects through the plume, measuring the distance from the volcano to the transect line, and then dividing this distance by the wind speed, the user can effectively enhance the temporal resolution of the $\mathrm{SO}_{2}$ emission rate data.

\subsection{Visual Analyses}

For each day of the study period, I examined available data from several different instruments in order to visualize the eruption as it progressed. I began by identifying the start of the eruption using images from the Spinning Enhanced Visible and Infrared Imager (SEVIRI) instrument, aboard the Meteosat-8 geostationary satellite. Following this, I examined all available day and night images from the Aqua and Terra MODIS instruments, typically four per day, for the length of the eruption. High resolution images from the Advanced Spaceborne Thermal Emission and Reflection Radiometer (ASTER) aboard Terra, the Enhanced Thematic Mapper Plus (ETM+) on the Landsat 7 platform, and the Advanced Land Imager (ALI) instrument on the EO-1 platform were available intermittently, so I also examined these whenever possible. 
For each daytime image, I examined visible, SWIR, and TIR data. For night-time overpasses, only TIR images are available. Following Rose and Ramsey (2009), I used a decorrelation stretch (DCS) of TIR wavelengths to differentiate water, ash, and $\mathrm{SO}_{2}$ in the volcanic plume. This was done in order to visually detect changes in eruption style. Similarly, I performed a principle components analysis on ALI visible and SWIR wavebands in order to distinguish between lava flows, thick scoria, and finer tephra in each image. Using ArcGIS software, I then examined these georeferenced images to estimate the areal extent of the tephra fall and lava flow. I then compared the latter results with estimates of lava volume from MODIS and $\mathrm{SO}_{2}$ mass from OMI in an attempt to understand the mass balance of the system.

\subsection{Error Considerations}

The dynamic row anomaly is the primary source of error for $\mathrm{OMI} \mathrm{SO}_{2}$ measurements. This created a gap in the data on several days where the row anomaly was obscuring a large part of the plume. A full-day data gap exists on 15 June, which also affects the total mass and flux results, especially as $\mathrm{SO}_{2}$ was likely high given the explosive state of the eruption at this time. For these reasons, the measured total $\mathrm{SO}_{2}$ mass should be considered a minimum value, although $\mathrm{SO}_{2}$ emission rates could still be derived from regions of the plume unaffected by the row anomaly. Examining data from other A-Train instruments (e.g., AIRS) could help to fill the gaps created by the row anomaly. A second source of error for $\mathrm{OMI} \mathrm{SO}_{2}$ mass and flux calculations comes from estimates of plume height and the wind speed at plume altitude. I estimated these values based primarily on HYSPLIT wind trajectory models derived from archived meteorological data. Although this technique seemed to work well for the majority of the study period, there were some days where the model and plume trajectories differed significantly. Ideally, installing local meteorological stations would improve these values, and thus our ability to accurately measure $\mathrm{SO}_{2}$ emissions during future eruptions. This is unrealistic, however, for several reasons including equipment cost and environmental factors resulting from political instability. One possibility for improving $\mathrm{SO}_{2}$ emission 
calculations would be to compare these UV estimates from OMI to those derived from IR, using MODIS or AIRS data. Inverse trajectory modeling could also be used to reconstruct the vertical profile of $\mathrm{SO}_{2}$, allowing more accurate height estimates for use in OMIplot (Hughes et al., 2012). Even so, due to limitations in the LF algorithm, column amounts may still be significantly underestimated when $\mathrm{SO}_{2}$ loadings are larger than 100 DU (Yang et al., 2007), which occurs on several occasions during the first part of the Nabro eruption.

The main natural source of error for IR lava effusion rate calculations comes from masking of the hot lava signal by meteorological clouds and the eruption plume. For this reason, like the $\mathrm{SO}_{2}$ mass above, the total volume of lava calculated from MODIS images should be considered a minimum value. Within the calculations, however, the primary source of error lies within the temperature estimates for the active lava flow. I attempted to address this error by exploring a range of values $\left(200-600^{\circ} \mathrm{C}\right)$, assuming that the real value may change over time and lies somewhere in between the high-temperature and low-temperature assumptions. Another source of error lies in the estimates for the physical properties of lava such as density, crystallinity and cooling range, which are crucial for deriving effusion rate from total surface heat flux. These were not known for Nabro, and therefore were estimated from published information on other volcanoes. Although not much can be done about either of these issues remotely, sampling the 2011 flow would provide better constraints on the physical properties of the lava, improving effusion rate calculations. A more detailed discussion on the limitations of satellitederived effusion rates can be found in Harris and Baloga (2009) and Harris et al. (1997, 2000, 2007, 2009).

A comprehensive field mapping campaign could allow detailed mapping of the lava flow, including thickness, giving a more accurate measure of lava volume. Similarly, a mapping campaign could yield estimates of scoria and tephra thickness, enabling creation of a detailed isopach map. Combining these results would provide a value for the total mass ejected during eruption. This, in turn, could be compared with the total $\mathrm{SO}_{2}$ emitted, lending insight into the sulfur content of the melt and the mass balance of the eruption. 
Creation of a new post-eruption DEM from synthetic aperture radar (SAR) data (then subtracting this from the pre-eruption SRTM DEM) might provide the best remote estimate of tephra and lava flow volumes; however, as these data are costly and not available to the general public, this method was not used in this study. Another low-cost alternative may be to match the observed tephra distribution at Nabro with ash fall models to constrain the erupted tephra mass.

\section{RESULTS}

The 2011 eruption of Nabro was bimodal in nature, beginning with approximately 3 days of explosive behavior before switching to a quieter effusive style. Unlike many explosive eruptions, the plume at Nabro did not exhibit a classic umbrella shape, but rather spread rapidly under the influence of wind. The $\mathrm{SO}_{2}$-rich plume did, however, reach lower stratospheric levels within the first few hours of eruption. Although there was little evidence of ash carried within the plume, the eruption produced a wide tephra fan covering hundreds of square kilometers. Following this explosive phase, a period of rapid effusion produced a dark lava flow $\sim 17 \mathrm{~km}$ in length. Figure 5 shows the large lava flow emanating from the southwest edge of the youngest nested crater, along with a mild plume and a wide, dark tephra fan.

Based on imagery from SEVIRI, the eruption began between 20:30 and 20:45 UTC on 12 June 2011. The first two days of the eruption were characterized by high $\mathrm{SO}_{2}$ emissions and an extensive plume, which deposited scoria and tephra in a wide fan for hundreds of kilometers. As the westward-trailing plume dominated satellite imagery in first few days, it is difficult to determine with any accuracy the time that lava first reached the surface. The first discernible hot pixels to be recorded by MODIS (band 32) appeared approximately 43 hours after the start of the eruption, on 14 June at 19:15 UTC. $\mathrm{SO}_{2}$ levels dropped just as lava effusion rates began to peak, and by 16 June the lava flow had almost reached its full lateral extent. Approximately six days after the eruption 
commenced, $\mathrm{SO}_{2}$ and lava effusion rates drop to moderate levels and continue in a moreor-less steady decline until the end of the study period on 26 July.

\subsection{Lava effusion rates from MODIS}

Instantaneous effusion rate and cumulative volume curves for active lava surface temperatures of 200,350 , and $600{ }^{\circ} \mathrm{C}$ are presented in Figure 6. These show a large effusive pulse in the first week of the eruption, followed by a gentle waning curve in subsequent weeks. From the perspective of average TADR, the effusion rate curve may be subdivided into three distinct periods: the initial high pulse during the first week of the eruption, followed by moderate TADRs during the second week, and an overall waning TADR for the remainder of the eruption.

Lava effusion begins slowly in the first two days, but then increases rapidly to peak by the 17 June at between $50.3 \mathrm{~m}^{3} \mathrm{~s}^{-1}\left(\mathrm{~T}=200{ }^{\circ} \mathrm{C}\right)$ and $81.6 \mathrm{~m}^{3} \mathrm{~s}^{-1}\left(\mathrm{~T}=600{ }^{\circ} \mathrm{C}\right)$. This may be considered a minimum, as the presence of four adjacent saturated pixels suggests that the actual effusion rate for this image may be much higher. The curve then wanes almost as quickly as it waxes, producing an average TADR for this period of $13.8-24.3 \mathrm{~m}^{3} \mathrm{~s}^{-1}$. The cumulative volume curve shows that almost 40 percent of the total measured lava extrusion occurred within this first week of eruption.

Activity settles to more moderate levels by the second week of the eruption. Average TADR decreases by almost half during this period, to $7.6-13.5 \mathrm{~m}^{3} \mathrm{~s}^{-1}$. Heavy cloud cover and a thick volcanic plume obscure much of the lava flow from 20 to 22 June, reducing the apparent effusion rate over this time. By the end of June, approximately 60 percent of the total measured lava volume was emplaced. Over the following three weeks, lava effusion wanes further to an average TADR of $4.6-8.1 \mathrm{~m}^{3} \mathrm{~s}^{-1}$. This average is enhanced slightly by a single peak of $19.5-34.4 \mathrm{~m}^{3} \mathrm{~s}^{-1}$ on the 6 July. The image contained two saturated pixels with a relatively clear sky and a scan angle of 23 degrees; in the absence of any other anomalies, I could see no reason to discard this value. Over the 5-week study period, lava effusion rate calculations from MODIS suggest a total volume between $1.86 \times 10^{7}$ and $3.28 \times 10^{7} \mathrm{~m}^{3}$ (total mass between $4.82 \times 10^{10}$ and $8.52 \times$ 
$10^{10} \mathrm{~kg}$, assuming a density of $2600 \mathrm{~kg} \mathrm{~m}^{-3}$ ). From these estimates of erupted mass, using the method outlined in Sparks et al. (1997), I have calculated a magnitude for this eruption ranging from 3.7 - 3.9 with intensities from 7.1 - 7.4 (Table 3).

\subsection{SO2 mass and flux from OMI}

Based on daily mass totals from OMI, the total mass of $\mathrm{SO}_{2}$ emitted between 13 June and 26 July 2011 was approximately $1824 \mathrm{KT}$. This value may be low, however, as the row anomaly obscured $\mathrm{SO}_{2}$ column data on several occasions. To compensate for this, I integrated under the $\mathrm{SO}_{2}$ flux curve (Figure 7) to arrive at a second value of $2299 \mathrm{KT}$ for this eruption. On the 13 June at approximately 00:02 UTC, the initial rate of SO2 emission was $\sim 6.8 \times 10^{5} \mathrm{t} / \mathrm{d}$, the highest rate for this eruption. This image also recorded the maximum $\mathrm{SO}_{2}$ mass for a single day, at $365 \mathrm{KT}$. Barring the initial high start, the shape of the $\mathrm{SO}_{2}$ flux curve mimics that of the lava effusion. The peaks are offset slightly in time, however, with the main pulse of lava emerging as the $\mathrm{SO}_{2}$ flux begins to wane. By the 17 June, four days into the eruption, $60 \%$ of the total measured $\mathrm{SO}_{2}$ mass had been released. Ten days later, gas emission was almost complete at $90 \%$ of the total. By 13 July, $\mathrm{SO}_{2}$ emissions had dropped below detectable levels, with one last pulse of 7 $\mathrm{KT}$ occurring on 26 July. Daily total $\mathrm{SO}_{2}$ mass values from OMI are given Appendix C.

\subsection{Visual analyses}

Analyses of visible and NIR post-eruption images from the ALI instrument reveal that the primary lava flow extended approximately $17 \mathrm{~km}$ from the vent, over an area of 22.1 $\mathrm{km}^{2}$. Thickness estimates from the flow margins suggest a minimum average thickness of $10 \mathrm{~m}$ over the flow (Goitom et al., 2011). Assuming the same density used in the effusion rate calculations $\left(2600 \mathrm{~kg} \mathrm{~m}^{-3}\right)$ yields a lava mass estimate of $\sim 5.75 \times 10^{11} \mathrm{~kg}$. This is an order of magnitude higher than that derived from IR effusion rate calculations. This would increase the eruption magnitude to 4.8 and the intensity to 8.2.

Visual analyses also revealed the presence of a thick tephra (scoria?) blanket inside the larger, thinner tephra fan (Figure 5,8). It appears as a dark feature in both visible and 
PCA images (Figure 8), stretching approximately $10-12 \mathrm{~km}$ from the active crater in a narrow arc. As ash fall tends to thin exponentially from the source (Sparks et al., 1997), the boundaries of these features often appear diffuse in satellite imagery, making them difficult to distinguish accurately. The areal extent of the large ash fan lies somewhere between $270-440 \mathrm{~km}^{2}$, including the thicker tephra blanket of $25-31 \mathrm{~km}^{2}$.

Table 4 contains the results of qualitative analyses of each satellite image for the first 7 days of the eruption. As described above, activity during this time period was highly variable, with thick ash fall, high $\mathrm{SO}_{2}$ emissions, and the development of a $17 \mathrm{~km}$ long lava flow. This table also includes information from other sources, such as the Smithsonian Institution. Data are organized by day, beginning with the seismic swarm on 12 June, before the onset of eruption.

\subsection{Mass balance}

Volatiles in the melt control the length and style of volcanic eruptions. While $\mathrm{SO}_{2}$ is the most easily measured gas, and thus used most in volcano monitoring, $\mathrm{H}_{2} \mathrm{O}$ is by far the more abundant gas species in volcanic systems. Water content and oxygen fugacity $\left(f \mathrm{O}_{2}\right)$ exhibit an important control on the solubility of $\mathrm{S}$ in melts (Metrich and Clocchiatti, 1996). Oxidized, $\mathrm{H}_{2} \mathrm{O}$-rich melts may accumulate a separate $\mathrm{S}$-bearing volatile phase at depth, which when erupted can lead to anomalously high $\mathrm{SO}_{2}$ compared to lava production, known as sulfur 'excess'. Work by Sharma et al. (2004) suggests that this is primarily true only for arc settings, however they propose that $\mathrm{CO}_{2}$-rich alkali non-arc magmas could exhibit this same behavior. Quantifying the relationship between effused lava and $\mathrm{SO}_{2}$ could therefore provide insight into the volatile content and source conditions of the melt.

In order for $4.82 \times 10^{10}$ to $8.52 \times 10^{10} \mathrm{~kg}$ of lava (derived from MODIS data) to outgas 1824 to $2299 \mathrm{KT}$ of $\mathrm{SO}_{2}$, the available melt would need to contain a minimum of 1.07 $2.38 \mathrm{wt} \%$ sulfur (S), or $10700-23800 \mathrm{ppm}$. Very little published data currently exist on the volatile content of Afar lavas, and none for Nabro. Clocchiatti et al. (1980) report peak sulfur concentrations from olivine-hosted melt inclusions of Ardoukoba of $\sim 0.12 \mathrm{wt} \%$ 
(1200 ppm). Based on previous eruptions, it is likely that the Nabro products will be quite alkaline (trachy-basalt or trachy-bas-andesite) (Wiart and Oppenheimer, 2004), and thus its S content may differ significantly from Ardoukoba basalts. However, as typical melt S concentrations range between 1000 and $4000 \mathrm{ppm}(0.1$ to $0.4 \mathrm{wt} \%$ ) (Metrich and Clocchiatti, 1996, Scaillet et al., 2003), the values above seem unreasonable without

invoking a separate S-rich vapor phase. Comparing the lava mass estimate of $5.75 \times 10^{11}$ $\mathrm{kg}$, derived from spatial analyses, to the $\mathrm{SO}_{2}$ totals yields a more reasonable $\mathrm{S}$ concentration range of $1600-2000 \mathrm{ppm}(0.16-0.20 \mathrm{wt} \%)$. This suggests that the MODIS IR method has significantly underestimated the amount of lava extruded during this eruption. See Table 3 for calculated masses and minimum sulfur contents, as well as the resulting eruption magnitudes and intensities.

\section{DISCUSSION}

The overall shape of the effusion rate curve (Figure 6) suggests rapid effusion of a pressurized system, followed by slow waning effusion as pressure is released and the system becomes more open (Harris et al., 2000, Wadge, 1981). According to Wadge (1981), this type of curve is characteristic of a pressurized dyke system. The waning shape of the overall effusion rate curve, coupled with the steadily diminishing cumulative volume rate, is analogous to fissure eruptions on Mts. Etna and Krafla, deemed by some other authors "Type I" eruptions (Harris et al., 2011, Harris et al., 2000). In the case of Nabro, this scenario would be a reasonable deduction, as earlier basaltic activity in the Afar has manifested as dyke-fed fissure eruptions (Ferguson et al., 2010, Wiart and Oppenheimer, 2004). Although views of the summit and erupting vent(s) are blocked by the thick ash and gas plume during the first few days, SAR images acquired over the length of the eruption (Grandin, 2012) show hints of fissure-like behavior in the form of small cones or craters, arranged linearly in a NW-SE pattern similar to the trend of other aligned cones and extensional features in the region (Wiart and Oppenheimer, 2004). Although it is not clear from remote sensing whether the eruption began as a single-vent 
or a fissure eruption, it appears that after the first few days both the plume and lava flows originate from a single large vent on the $\mathrm{SW}$ rim of the young nested crater at the summit of the volcano.

After comparing the lava effusion and $\mathrm{SO}_{2}$ emission rates and their cumulative mass curves, I have broken the eruption down into four stages (Figure 9). The first stage is characterized by high $\mathrm{SO}_{2}$ emission, ash deposition and an extensive volcanic plume. This was the initial conduit-clearing stage, where degassing pressure finally overcame the old solidified plug, breaking the surface and blowing out the summit vent. $\mathrm{High} \mathrm{SO}_{2}$ emissions coupled with low lava effusion rates in the early days of the eruption suggest activity may have started with a gas-dominated eruption style, such as Hawaiian fire fountaining.

After the initial throat-clearing and rapid draining of the conduit, the newly degassed magma escaped quickly to the surface, driven by decompression from above and exsolution from below. This is evident in stage two (beginning between 12:00 and 17:00 UTC on 16 June), when the rate of $\mathrm{SO}_{2}$ emission drops sharply from $\sim 4 \times 10^{5} \mathrm{t} / \mathrm{d}$ to $\sim 3.1$ $\times 10^{4} \mathrm{t} / \mathrm{d}$. This coincides with an increase in lava effusion from $2.7-5.3 \mathrm{~m}^{3} \mathrm{~s}^{-1}$ to 24.0 $42.9 \mathrm{~m}^{3} \mathrm{~s}^{-1}$. Balancing the former values yields a sulfur concentration requirement of $32780-16700 \mathrm{ppm}$ at the end of stage one, demonstrating a clear excess in $\mathrm{SO}_{2}$ over lava at this time. The latter values, on the other hand, yield a concentration requirement of $1600-2900 \mathrm{ppm}$ at the beginning of stage two. This abrupt change in style is evident in MODIS images from 16 June, which show a plume-dominated eruption in the morning followed by long lava flows with little-to-no plume presence by nightfall. SEVIRI data also show a strong, high altitude plume during the morning of 16 June, which stops abruptly around 14:00 UTC.

By stage three (beginning 19 June), lava effusion and gas emission had both reached moderate levels, averaging $8.7 \mathrm{~m}^{3} \mathrm{~s}^{-1}$ and $1.1 \times 10^{5} \mathrm{t} / \mathrm{d}$, respectively. The slopes of the cumulative mass curves show that the percent rate of output (slope of the curve) for these products was similar during this time, suggesting that gas-rich magma was beginning to 
reach the surface. Activity began to wane at the end of June. One interpretation is that rapid ascent and degassing during stage 3 may have lead to a decrease in magma supply, such that the magma in the upper part of the conduit eventually degassed before it reached the surface, raising the viscosity and slowing the ascent from depth. The cumulative mass curve shows that $\mathrm{SO}_{2}$ emission was almost finished by the end of June, as more than 90 percent of the total $\mathrm{SO}_{2}$ emitted had already been released from the system. Lava effusion, though reduced, continued at a fairly steady pace, between 4.6 $8.1 \mathrm{~m}^{3} \mathrm{~s}^{-1}$, producing a further 35 percent of the measured total over the last three weeks of the eruption. Preliminary SAR analyses suggest increased outflow and possible collapse of the main vent sometime during the third or fourth week of the eruption (Grandin, 2012). The earlier image, taken on 1 July, shows a ridge- or dome-like feature at the location of the crater vent. The next image, taken on 12 July, shows a sunken, bowl-like shape at the vent, and an increase in the surrounding lava flows. This may explain the spike in lava effusion of $19.5-34.4 \mathrm{~m}^{3} \mathrm{~s}^{-1}$, seen on $6 \mathrm{July}$, which may have been prefaced by a minor increase in $\mathrm{SO}_{2}$ mass the previous day. The main eruption eventually stopped near the end of July. However, MODVOLC thermal alerts continued to appear sporadically for almost a year after the eruption had ceased. Although no detectable levels of $\mathrm{SO}_{2}$ were present during these times, the alert pixels corresponded to the location of the main eruptive vent, potentially suggesting the presence of small flows or a slow-churning lava lake.

Effusion rate calculations from MODIS yield a total lava mass of $4.82 \times 10^{10}$ to $8.52 \mathrm{x}$ $10^{10} \mathrm{~kg}$, requiring an excessively high minimum sulfur content for the melt of $1.07-2.38$ $\mathrm{wt} \%$. Post-eruption ALI images suggest a total lava mass of $5.75 \times 10^{11} \mathrm{~kg}$, an order of magnitude higher than those derived from MODIS IR. Although this latter value yields more a reasonable minimum $\mathrm{S}$ content of $0.16-0.20 \mathrm{wt} \%$, a mass balance should not consider lava effusion alone. The wide tephra fan and thick scoria deposits suggest that plume ejecta make up a significant portion of the erupted materials. Although these mass estimates do not consider mass from tephra fall, they nonetheless display broad agreement between the erupted mass and that expected by the total $\mathrm{SO}_{2}$ emission by 
returning reasonable minimum sulfur concentration values (i.e. no 'excess' sulfur). It seems reasonable then to infer that nearly all of the degassed magma was erupted at the surface. Based solely on the mass of erupted lava, the magnitude of the 2011 eruption of Nabro was at least 3.7 to 4.8 , making this the one of the largest recorded eruptions in the Afar. When one considers the addition of the extensive tephra fall, this could easily be considered the second largest historical eruption in Africa after the 1861 Dubbi eruption (Wiart and Oppenheimer, 2000).

There are many drawbacks to relying solely on satellite remote sensing. The trade-off between spatial, spectral and temporal resolution means that the specific information we want may not always be available. Changing environmental conditions over the volcano, such as cloud cover, new flows and vegetation, can render a sensor effectively blind, and instrument malfunctions like the OMI row anomaly may cause us to miss vital information. Calculations from satellite data, such as effusion rate and gas concentration, rely heavily on assumptions about the state of the environment and the properties of the material in question, which can at times lead to inaccurate or even incorrect results. Despite these limitations, satellite remote sensing remains an extremely valuable tool for studying and monitoring active volcanoes. By utilizing a wide range of the electromagnetic spectrum, from RADAR to UV, satellite instruments provide information about ground displacement, volcanic gas concentrations, and heat flux to the surface, enabling scientists to study and monitor volcanoes from anywhere in the world. This is especially important for remote volcanoes, which are often difficult or impossible to access safely.

\section{CONCLUSION}

Despite the absence of ground information, freely available satellite data allowed assessment of the size, style and evolution of the Nabro eruption. This included quantitative analyses of lava volume and effusion rates, $\mathrm{SO}_{2}$ mass and flux, and the areal extent of tephra fall. From these data, it is clear that this eruption was bimodal in nature, 
beginning explosively, followed by a period of rapid lava production, which then settles into moderate effusion. During the $\sim 6$ weeks of its eruption, Nabro produced 1824 $2299 \mathrm{KT}$ of $\mathrm{SO}_{2}$ and $1.86 \times 10^{7}-3.28 \times 10^{7} \mathrm{~m}^{3}$ of lava, as well as a tephra blanket covering $270-440 \mathrm{~km}^{2}$. With its large lava flow volume combined and thick, extensive tephra fall, the 2011 eruption of Nabro may be considered the second largest historical eruption in Africa. Work such as this highlights the importance of public access to free satellite remote sensing data for the study and monitoring of volcanoes.

\section{REFERENCES}

ALlARD, P., CARBOnElle, J., MÉTRICH, N., LOYER, H. \& ZETTWOOG, P. 1994. Sulphur output and magma degassing budget of Stromboli volcano. Nature 326-330.

BARBERI, F., BONATTI, E., MARINELLI, G. \& VARET, J. 1974. Transverse tectonics during the split of a continent: Data from Afar rift. Tectonophysics, 23, 17-29.

BARBERI, F., BORSI, S., FERRARA, G., MARINELLI, G. \& VARET, J. 1970. Relations between tectonics and magmatology in the northern Danakil Depression (Ethiopia). Royal Society of London Philosophical Transactions, 267, 293-311.

BARBERI, F., GIGLIA, G., MARINELLI, G., SANTACROCE, R., TAZIEFF, H. \& VARET, J. 1971. Geological map of the Danakil Depression (Northern Afar, Ethiopia). La Celle Saint Cloud, France: CNR-CNRS.

BARBERI, F. \& VARET, J. 1977. Volcanism of Afar: Small-scale plate tectonics implications. Geological Society of America Bulletin, 88, 1251.

BOURASSA, A. E., ROBOCK, A., RANDEL, W. J., DESHLER, T., RIEGER, L. A., LLOYD, N. D., LLEWELLYN, E. J. \& DEGENSTEIN, D. A. 2012. Large volcanic aerosol load in the stratosphere linked to Asian monsoon transport. Science, 337, 78-81.

BOURASSA, A. E., ROBOCK, A., RANDEL, W. J., DESHLER, T., RIEGER, L. A., LLOYD, N. D., LLEWELLYN, E. J. \& DEGENSTEIN, D. A. 2013. Response to Comments on "Large Volcanic Aerosol Load in the Stratosphere Linked to Asian Monsoon Transport". Science, 339, 647-647.

CARN, S. A. \& BLUTH, G. J. S. 2003. Prodigious sulfur dioxide emissions from Nyamuragira volcano, D.R. Congo. Geophysical Research Letters, 30.

CARN, S. A., KRUEGER, A. J., KROTKOV, N. A., YANG, K. \& EVANS, K. 2008. Tracking volcanic sulfur dioxide clouds for aviation hazard mitigation. Natural Hazards, 51, 325343.

CARN, S. A. \& PRATA, F. J. 2010. Satellite-based constraints on explosive SO2 release from Soufrière Hills Volcano, Montserrat. Geophysical Research Letters, 37, n/a-n/a.

CLOCCHIATTI, R., MÉTRICH, N. \& WEISS, J. 1980. Petrologie et mineralogie des basaltes d'Asal, Afar. Bulletin CNRS-PIRPSEV, 18.

DENLINGER, R. P. 1997. A dynamic balance between magma supply and eruption rate at Kilauea volcano, Hawaii. Journal of Geophysical Research, 102, 18091.

DRAXLER, R. R. 1999. HYSPLIT4 user's guide. NOAA Air Resources Laboratory, Silver Spring, MD. : NOAA Tech. Memo. . 
DRAXLER, R. R. \& HESS, G. D. 1997. Description of the HYSPLIT_4 modeling system. NOAA Air Resources Laboratory, Silver Spring, MD: NOAA Tech. Memo. .

DRAXLER, R. R. \& HESS, G. D. 1998. An overview of the HYSPLIT_4 modeling system of trajectories, dispersion, and deposition. Aust. Meteor. Mag., 47, 295-308.

DRAXLER, R. R. \& ROLPH, G. D. 2013. HYSPLIT (HYbrid Single-Particle Lagrangian Integrated Trajectory) Model access via NOAA ARL READY Website (http://ready.arl.noaa.gov/HYSPLIT.php). NOAA Air Resources Laboratory, Silver Spring, MD.

DVORAK, J. J. \& DZURISIN, D. 1993. Variations in magma supply rate at Kilauea Volcano, Hawaii. Journal of Geophysical Research, 98, 22255-22268.

EDMONDS, M., AIUPPA, A., HUMPHREYS, M., MORETTI, R., GUIDICE, G., MARTIN, R. S., HERD, R. A. \& CHRISTOPHER, T. 2010. Excess volatiles supplied by mingling of mafic magma at an andesite arc volcano. Geochemistry, Geophysics, Geosystems, 11, Q04005.

FERGUSON, D. J., BARNIE, T. D., PYLE, D. M., OPPENHEIMER, C., YIRGU, G., LEWI, E., KIDANE, T., CARN, S. \& HAMLING, I. 2010. Recent rift-related volcanism in Afar, Ethiopia. Earth and Planetary Science Letters, 292, 409-418.

FROMM, M., NEDOLUHA, G. \& CHARVAT, Z. 2013. Comment on "Large volcanic aerosol load in the stratosphere linked to Asian monsoon transport". Science, 339, 647; author reply 647.

GOITOM, B., HAMMOND, J., KIBROM, G., OPPENHEIMER, C. \& YOHANNES, E. 2011. "Mechanisms and implications of the 2011 eruption of Nabro volcano, Eritrea": Report on fieldwork carried out in October 2011.

GRANDIN, R. 2012. Nabro volcano mid 2011 eruption, What can SAR tell us? Nabro 2012 Workshop.

GRANDIN, R., SOCQUET, A., BINET, R., KLINGER, Y., JACQUES, E., DE CHABALIER, J. B., KING, G. C. P., LASSERRE, C., TAIT, S., TAPPONNIER, P., DELORME, A. \& PINZUTI, P. 2009. September 2005 Manda Hararo-Dabbahu rifting event, Afar (Ethiopia): Constraints provided by geodetic data. Journal of Geophysical Research, 114.

HARRIS, A. 2013. Electronic Supplement 7 - Conversion from spectral radiance to lava area, heat flux and discharge rate. Thermal Remote Sensing of Active Volcanoes. A User's Manual. First Edition 2013 ed.: Cambridge University Press.

HARRIS, A., STEFFKE, A., CALVARI, S. \& SPAMPINATO, L. 2011. Thirty years of satellitederived lava discharge rates at Etna: Implications for steady volumetric output. Journal of Geophysical Research, 116.

HARRIS, A. J. L. \& BALOGA, S. M. 2009. Lava discharge rates from satellite-measured heat flux. Geophysical Research Letters, 36.

HARRIS, A. J. L., BLAKE, S. \& ROTHERY, D. A. 1997. A chronology of the 1991 to 1993 Mount Etna eruption using advanced very high resolution radiometer data: Implications for real-time thermal volcano monitoring. Journal of Geophysical Research, 102, 79858003.

HARRIS, A. J. L., DEHN, J. \& CALVARI, S. 2007. Lava effusion rate definition and measurement: a review. Bulletin of Volcanology, 70, 1-22.

HARRIS, A. J. L., MURRAY, J. B., ARIES, S. E., DAVIES, M. A., FLYNN, L. P., WOOSTER, M. J., WRIGHT, R. \& ROTHERY, D. A. 2000. Effusion rate trends at Etna and Krafla and their implications for eruptive mechanisms. Journal of Volcanology and Geothermal Research, 102, 237-270.

HARRIS, A. J. L. \& ROWLAND, S. K. 2001. FLOWGO: a kinematic thermorheological model for lava flowing in a channel. Bulletin of Volcanology, 63, 20-44. 
HARRIS, A. J. L. \& STEVENSON, D. 1997. Magma budgets and steady-state activity of Vulcano and Stromboli Volcanoes. Geophysical Research Letters, 24, 1043-1046.

HUGHES, E. J., SPARLING, L. C., CARN, S. A. \& KRUEGER, A. J. 2012. Using horizontal transport characteristics to infer an emission height time series of volcanic SO2. Journal of Geophysical Research: Atmospheres, 117, n/a-n/a.

KEIR, D., HAMLING, I. J., AYELE, A., CALAIS, E., EBINGER, C., WRIGHT, T. J., JACQUES, E., MOHAMED, K., HAMMOND, J. O. S., BELACHEW, M., BAKER, E., ROWLAND, J. V., LEWI, E. \& BENNATI, L. 2009. Evidence for focused magmatic accretion at segment centers from lateral dike injections captured beneath the Red Sea rift in Afar. Geology, 37, 59-62.

KROTKOV, N. A., CARN, S. A., KRUEGER, A. J., BHARTIA, P. K. \& YANG, K. 2006. Band Residual Difference Algorithm for Retieval of SO2 From the Aura Ozone Monitoring Instrument (OMI). IEEE TRANSACTIONS ON GEOSCIENCE AND REMOTE SENSING, 44.

LAUTZE, N. C., HARRIS, A. J. L., BAILEY, J. E., RIPEPE, M., CALVARI, S., DEHN, J., ROWLAND, S. K. \& EVANS-JONES, K. 2004. Pulsed lava effusion at Mount Etna during 2001. Journal of Volcanology and Geothermal Research, 137, 231-246.

LEVELT, P. F., VAN DEN OORD, G. H. J., DOBBER, M. R., MALKKI, A., VISSER, H., DE VRIES, J., STAMMES, P., LUNDELL, J. O. V. \& SAARI, H. 2006. The Ozone Monitoring Instrument. IEEE TRANSACTIONS ON GEOSCIENCE AND REMOTE SENSING, 44, 1093-1101.

METRICH, N. \& CLOCCHIATTI, R. 1996. Sulfur abundance and its speciation in oxidized alkaline melts. Geochimica et Cosmochimica Acta, 60, 4151-4160.

OPPENHEIMER, C., MCGONIGLE, A. J. S., ALLARD, P., WOOSTER, M. J. \& TSANEV, V. 2004. Sulfur, heat, and magma budget of Erta 'Ale lava lake, Ethiopia. Geology, 32, 509.

PAGLI, C., WRIGHT, T. J., EBINGER, C. J., YUN, S.-H., CANN, J. R., BARNIE, T. \& AYELE, A. 2012. Shallow axial magma chamber at the slow-spreading Erta Ale Ridge. Nature Geoscience, 5, 284-288.

PIERI, D. C. \& BALOGA, S. 1986. Eruption rate, area, and length relationships for some hawaiian lava flows. Journal of Volcanology and Geothermal Research, 30, 29-45.

RIPEPE, M., MARCHETTI, M., ULIVIERI, G., HARRIS, A., DEHN, J., BURTON, M., CALTABIANO, T. \& SALERNO, G. 2005. Effusive to explosive transition during the 2003 eruption of Stromboli volcano. . Geology, 33, 341-344.

ROLPH, G. D. 2013. Real-time Environmental Applications and Display sYstem (READY) Website (http://ready.arl.noaa.gov). NOAA Air Resources Laboratory, Silver Spring, MD.

ROSE, S. \& RAMSEY, M. 2009. The 2005 eruption of Kliuchevskoi volcano: Chronology and processes derived from ASTER spaceborne and field-based data. Journal of Volcanology and Geothermal Research, 184, 367-380.

ROWLAND, J. V., BAKER, E., EBINGER, C., KEIR, D., KIDANE, T., BIGGS, J., HAYWARD, N. \& WRIGHT, T. J. 2007. Fault growth at a nascent slow-spreading ridge: 2005 Dabbahu rifting episode, Afar. Geophysical Journal International, 1226-1246.

ROWLAND, S. K., GARBIEL, H. \& HARRIS, A. J. L. 2005. Lengths and hazards from channelfed lava flows on Mauna Loa, Hawai'i, determined from thermal and downslope modeling with FLOWGO. Bulletin of Volcanology, 67, 634-647.

SCAILLET, B., LUHR, J. F. \& CARROLL, M. R. 2003. Petrological and volcanological constraints on volcanic sulfur emissions to the atmosphere. In: ROBOCK, A. \& OPPENHEIMER, C. (eds.) Volcanism and the Earth's Atmosphere. Washington D.C.: AGU.

SCHILLING, J. G. 1973. Afar mantle plume: Rare earth evidence. Nature, 242, 2-5. 
SHARMA, K., BLAKE, S. \& SELF, S. 2004. SO2emissions from basaltic eruptions, and the excess sulfur issue. Geophysical Research Letters, 31.

SMITHSONIAN, I. 2011. Nabro: First historically observed eruption began 13 June 2011 [Online]. [Accessed 09 36].

SPARKS, R. S., BIGGS, J. \& NEUBERG, J. W. 2012. Monitoring volcanoes. Science, 335, $1310-1$.

SPARKS, R. S. J., BURSIK, M. I., CAREY, S. N., GILBERT, J. S., GLAZE, L. S., SIGURDSSON, H. \& WOODS, A. W. 1997. Volcanic plumes, Wiley.

VERNIER, J. P., THOMASON, L. W., FAIRLIE, T. D., MINNIS, P., PALIKONDA, R. \& BEDKA, K. M. 2013. Comment on "Large volcanic aerosol load in the stratosphere linked to Asian monsoon transport". Science, 339, 647; author reply 647.

WADGE, G. 1981. The variation of magma discharge during basaltic eruptions. Journal of Volcanology and Geothermal Research, 11, 139-168.

WADGE, G., WALKER, G. P. L. \& GUEST, J. E. 1975. The output of the Etna volcano. Nature, $255,385-387$.

WADGE, G., YOUNG, P. A. V. \& MCKENDRICK, I. J. 1994. Mapping lava flow hazards using computer simulation. Journal of Geophysical Research, 99, 489-504.

WALLACE, P. J. 2001. Volcanic SO2 emissions and the abundance and distribuition of exsolved gas in magma bodies. Journal of Volcanology and Geothermal Research, 108, 85-106.

WIART, P. \& OPPENHEIMER, C. 2000. Largest known historical eruption in Africa: Dubbi volcano, Eritrea, 1861. Geology, 28, 291.

WIART, P. \& OPPENHEIMER, C. 2004. Large magnitude silicic volcanism in north Afar: the Nabro Volcanic Range and Ma'alalta volcano. Bulletin of Volcanology, 67, 99-115.

WIART, P. A. M., OPPENHEIMER, C. \& FRANCIS, P. 2000. Eruptive history of Dubbi volcano, northeast Afar (Eritrea), revealed by optical and SAR image interpretation. International Journal of Remote Sensing, 21, 911-936.

WRIGHT, R., BLAKE, S., HARRIS, A. J. L. \& ROTHERY, D. A. 2001. A simple explanation for the space-based calculation of lava eruption rates. Earth and Planetary Science Letters, 192, 223-233.

WRIGHT, R., FLYNN, L., GARBEIL, H., HARRIS, A. \& PILGER, E. 2002. Automated volcanic eruption detection using MODIS. Remote Sensing of Environment, 82.

WRIGHT, R., FLYNN, L. P., GARBEIL, H., HARRIS, A. J. L. \& PILGER, E. 2004. MODVOLC: near-real-time thermal monitoring of global volcanism. Journal of Volcanology and Geothermal Research, 135, 29-49.

WRIGHT, T. J., EBINGER, C., BIGGS, J., AYELE, A., YIRGU, G., KEIR, D. \& STORK, A. 2006. Magma-maintained rift segmentation at continental rupture in the 2005 Afar dyking episode. Nature, 442, 291-4.

YANG, K., KROTKOV, N. A., KRUEGER, A. J., CARN, S. A., BHARTIA, P. K. \& LEVELT, P. F. 2007. Retrieval of large volcanic SO2columns from the Aura Ozone Monitoring Instrument: Comparison and limitations. Journal of Geophysical Research, 112.

YOUNG, P. \& WADGE, G. 1990. FLOWFRONT: simulation of a lava flow. Computational Geoscience, 16, 1171-1191. 


\section{TABLES}

Table 1: List of eruptions in the Afar Triangle and Red Sea that have occurred since 2005, including their erupted volumes and magnitudes.

\begin{tabular}{|l|l|l|l|c|l|}
\hline Year & Volcano & Type & Eruption Style & Volume $\left(\times 10^{6} \mathrm{~m}^{3}\right)$ & Reference \\
\hline 2005 & Dabbahu & Axial & Felsic, minor explosive & 540 & Grandin et al. 2009 \\
\hline 2007 & Manda Hararo & Axial & Basaltic, fissure & $4.6 \pm 1.5$ & Ferguson et al. 2010 \\
\hline 2008 & Alu / Dalaffilla & Axial & Basaltic, fissure & 25.4 & Pagli et al. 2012 \\
\hline 2009 & Manda Hararo & Axial & Basaltic, fissure & $11 \pm 1.8$ & Ferguson et al. 2010 \\
\hline 2011 & Nabro & Marginal & Bimodal & $19-221^{*}$ & IR + spatial analyses \\
\hline
\end{tabular}

*Values for the Nabro eruption consider the lava flow only, and do not include mass from plume ejecta.

Table 2: Assumed parameter values used to calculate lava effusion rates, in order of appearance.

\begin{tabular}{|c|c|c|c|c|}
\hline Parameter & Symbol & Value & Unit & Reference \\
\hline Emissivity & $\varepsilon$ & 0.96 & -- & Harris et al. 2007 \\
\hline Stefan-Boltzmann constant & $\sigma$ & $5.67 \times 10^{-8}$ & $\mathrm{~W} \mathrm{~m}^{-2} \mathrm{~K}^{-4}$ & Harris et al. 1997 \\
\hline Convective heat transfer coefficient & $h_{c}$ & 10 & $\mathrm{~W} \mathrm{~m}^{-2} \mathrm{~K}^{-1}$ & Harris et. al. 2005 \\
\hline Ambient air temperature & $\mathrm{T}_{\mathrm{a}}$ & 298.15 & ${ }^{\circ} \mathrm{K}$ & Harris et al. 1997 \\
\hline Lava density & $\rho$ & 2600 & $\mathrm{~kg} \mathrm{~m}^{-3}$ & Harris et al. 2007 \\
\hline Specific heat capacity & $C_{p}$ & 1150 & $\mathrm{~J} \mathrm{~kg}^{-1} \mathrm{~K}^{-1}$ & Harris et al. 2007 \\
\hline Temperature change from eruption to flow stop & $\Delta T$ & 150 & ${ }^{\circ} \mathrm{K}$ & Harris et al. 1997 \\
\hline Average mass fraction of crystals & $\phi$ & 0.4 & -- & Harris et al. 1997 \\
\hline Latent heat of crystallisation & $C_{L}$ & $3.50 \times 10^{5}$ & $\mathrm{~J} \mathrm{~K}^{-1}$ & Harris et. al. 2005 \\
\hline
\end{tabular}

Table 3: Results of mass balance calculations. These reflect the lava flow only, and do not consider mass from plume ejecta.

\begin{tabular}{|l|r|r|r|r|r|}
\hline \multicolumn{7}{|c|}{ Mass Balance } \\
\hline \multirow{2}{*}{ Lava volume derivation method } & \multicolumn{1}{|c|}{ Mass } & \multicolumn{2}{|c|}{ Minimum S wt \% in melt } & Magnitude & Intensity \\
\cline { 2 - 6 } & $\left(\mathrm{kg} \mathrm{\times 10^{12 } )}\right)$ & for $1824 \mathrm{KT} \mathrm{SO}_{2}$ & for $2711 \mathrm{KT} \mathrm{SO}_{2}$ & (from Sparks et al. 1997) \\
\hline MODIS $\left(\mathrm{T}=200^{\circ} \mathrm{C}\right)$ & 0.05 & $1.89 \%$ & $2.38 \%$ & 3.68 & 7.17 \\
\hline MODIS $\left(\mathrm{T}=600^{\circ} \mathrm{C}\right)$ & 0.09 & $1.07 \%$ & $1.35 \%$ & 3.93 & 7.41 \\
\hline ALI spatial analysis & 0.47 & $0.16 \%$ & $0.20 \%$ & 4.76 & 8.24 \\
\hline
\end{tabular}


Table 4: Qualitative observations detailing the first seven days of the eruption.

\begin{tabular}{|c|c|c|}
\hline Date & Observations & Sources \\
\hline $\begin{array}{l}12 \text { June } 2011 \\
\text { (seismic } \\
\text { precursors) }\end{array}$ & $\begin{array}{l}\text { Seismic swarm: beginning 18:37 local time. } 102 \text { earthquakes from M2.7 - } 5.4 \text { within } \\
\text { the NVR, the majority focused around Nabro. Quakes cluster at } \sim 7 \mathrm{~km} \text { depth and near } \\
\text { surface. Three earthquakes }>M 5 \text {, the largest of which at } 10 \mathrm{~km} \text { depth below Nabro. }\end{array}$ & $\begin{array}{l}\text { Goitom } 2011 \\
\text { (presentation); } \\
\text { Smithsonian } 2011\end{array}$ \\
\hline $\begin{array}{l}13 \text { June - } \\
\text { first day of } \\
\text { eruption (thick } \\
\text { ash plume, high } \\
\mathrm{SO}_{2} \text { release) }\end{array}$ & $\begin{array}{l}\text { First day of eruption. Plume detected from space (SEVIRI) at midnight local time (12 } \\
\text { June, 21:00 UTC). Thick ash plume visible in MODIS images, reaches upper } \\
\text { troposphere / lower stratosphere. SO2 detected at } 365 \mathrm{KT} \text {. The Eritrean Ministry for } \\
\text { Information (EMI) reports ash fall of hundreds of square kilometers, and evacuation of } \\
\text { residents from the area due to ash fall. Plume drifts over } 1000 \mathrm{~km} \text { to Sudan. }\end{array}$ & $\begin{array}{l}\text { Observations from } \\
\text { MODIS, SEVIRI and OMI; } \\
\text { Smithsonian } 2011\end{array}$ \\
\hline $\begin{array}{l}14 \text { June } \\
\text { (thick ash, first } \\
\text { lava hot spot) }\end{array}$ & $\begin{array}{l}\text { Evacuations continue. According to EMI, all residents are moved to safety. Satellite } \\
\text { images show clear ash plume (MODIS, ALI), and Terra MODIS shows first sign of lava } \\
\text { flow at 19:17 UTC. Lava effusion starts low. } \mathrm{SO}_{2} \text { drops to } 166 \mathrm{KT} \text {. }\end{array}$ & $\begin{array}{l}\text { Observations from } \\
\text { MODIS, ALI and OMI; } \\
\text { Smithsonian } 2011\end{array}$ \\
\hline 15 June & $\begin{array}{l}\text { Flights cancelled in northern Africa due to ash. Plume shows strong } \mathrm{SO}_{2} \text { signal. } \\
\text { Tephra fan seen from MODIS visual images. Hot spot evident at the summit. }\end{array}$ & $\begin{array}{l}\text { Observations from } \\
\text { MODIS; Smithsonian } \\
2011\end{array}$ \\
\hline $\begin{array}{l}16 \text { June } \\
\text { (change to } \\
\text { effusive) }\end{array}$ & $\begin{array}{l}\text { Plume composed of water and gas. High SO2 at } 344 \mathrm{KT} \text {. Apparent effusion rate } \\
\text { increases significantly. By evening MODIS images reveal the main lava flow with its } \\
\text { characteristic check shape. }\end{array}$ & $\begin{array}{l}\text { Observations from } \\
\text { MODIS }\end{array}$ \\
\hline 17 June & $\begin{array}{l}\mathrm{SO}_{2} \text { flux drops significantly. No apparent atmospheric or environmental explanation } \\
\text { for the drop. Meanwhile, lava effusion peaks to the highest value for the eruption at } \\
66 \mathrm{~m}^{3} \mathrm{~s}^{-1} \text {. }\end{array}$ & $\begin{array}{l}\text { Observations from } \\
\text { MODIS }\end{array}$ \\
\hline $\begin{array}{l}18 \text { June } \\
\text { (possible lava } \\
\text { tube) }\end{array}$ & $\begin{array}{l}\text { Plume composed of water and gas. Moderate } \mathrm{SO}_{2} \text { emissions at } 88 \mathrm{KT} \text {. Lava effusion } \\
\text { rate drops sharply to } 19 \mathrm{~m}^{3} \mathrm{~s}^{-1} \text {. MODIS TIR image at } 23: 15 \text { UTC shows bifurcated } \\
\text { hotspot (probably summit and flank), not plume or cloud related. }\end{array}$ & $\begin{array}{l}\text { Observations from } \\
\text { MODIS }\end{array}$ \\
\hline 19 June & $\begin{array}{l}\text { Plume composed of water, gas and fine ash. } \mathrm{SO}_{2} \text { and lava effusion still moderate. In } \\
\text { the morning, long, narrow, brown ash plume is visible in MODIS images. Evening } \\
\text { ASTER image shows small, vertical plume composed primarily of water and gas. }\end{array}$ & $\begin{array}{l}\text { Observations from } \\
\text { MODIS and ASTER. }\end{array}$ \\
\hline
\end{tabular}




\section{FIGURES}

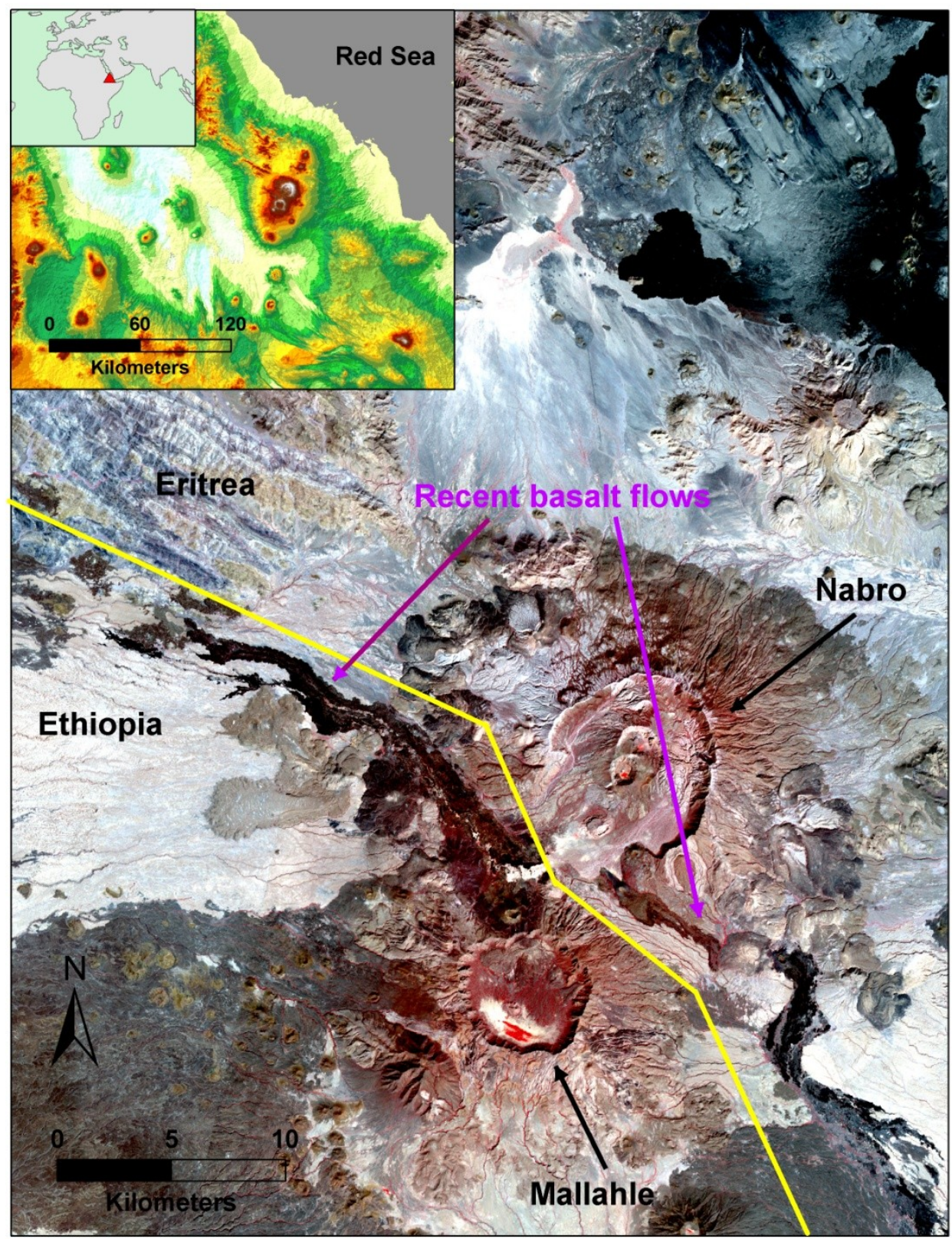

Figure 1: ASTER false color image from 14 April 2011 (VNIR bands 3, 2, 1 (RGB)) showing Nabro, Eritrea and Mallahle, Ethiopia (international border shown in yellow). Recent basalt flows are indicated by purple arrows. The middle inset shows the topography surrounding the NVR, with colors scaled every $100 \mathrm{~m}$ from light blue $(-230$ $\mathrm{m}$, a.s.1.) to white (2200 m, a.s.1.). 


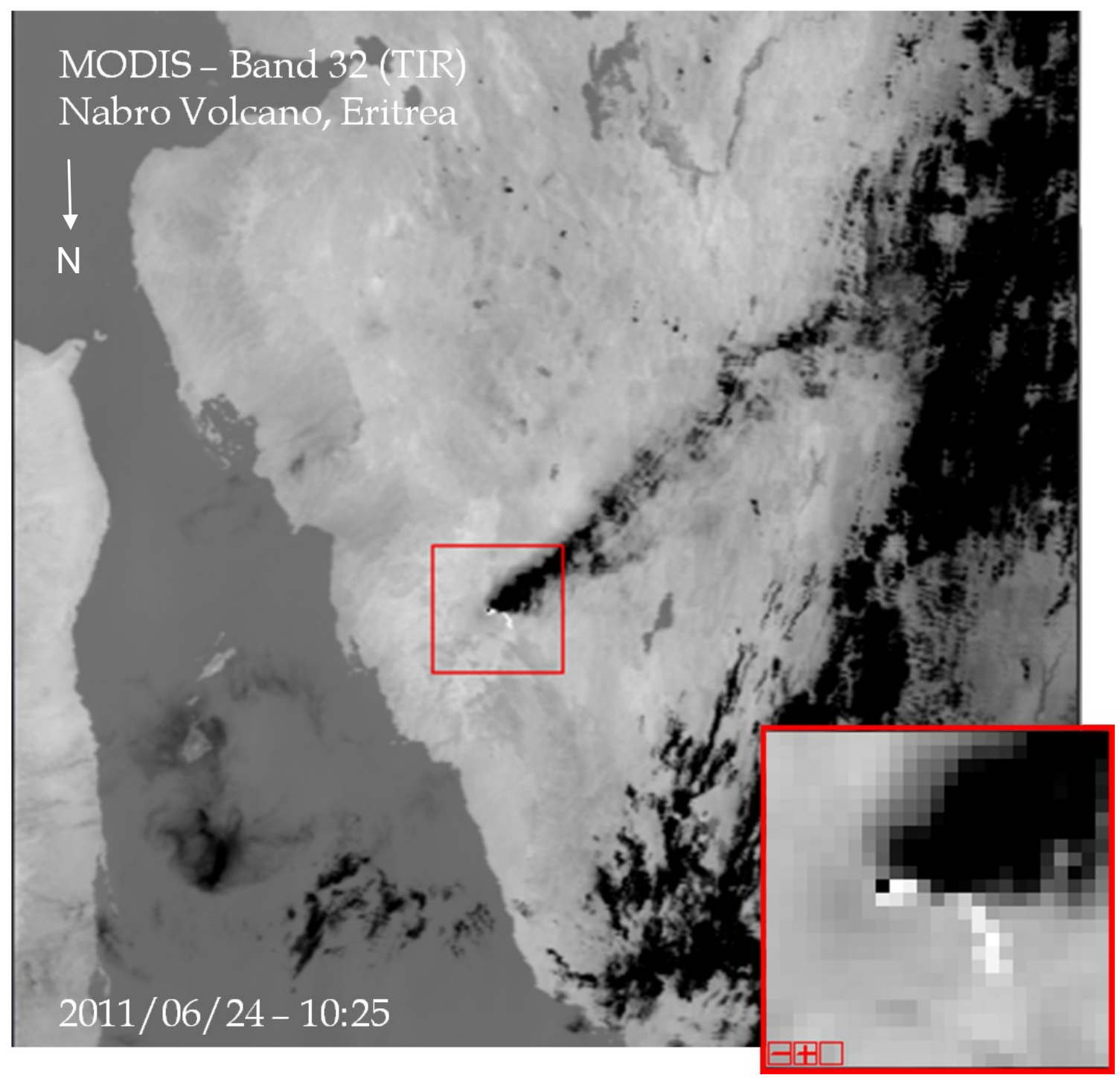

Figure 2: Example raw Level 1B MODIS Band 32 image over Nabro, Eritrea. Pixels are roughly $1 \mathrm{x} 1 \mathrm{~km}$. White pixels denote areas of high temperature, in this case the main lava flow off the southwest flank of Nabro. Dark pixels show areas of relative cold, such as meteoric cloud. The volcanic plume is seen clearly blowing to the southwest. The single saturated pixel (black) that appears on the edge of the flow, corresponds to the location of the summit vent. 

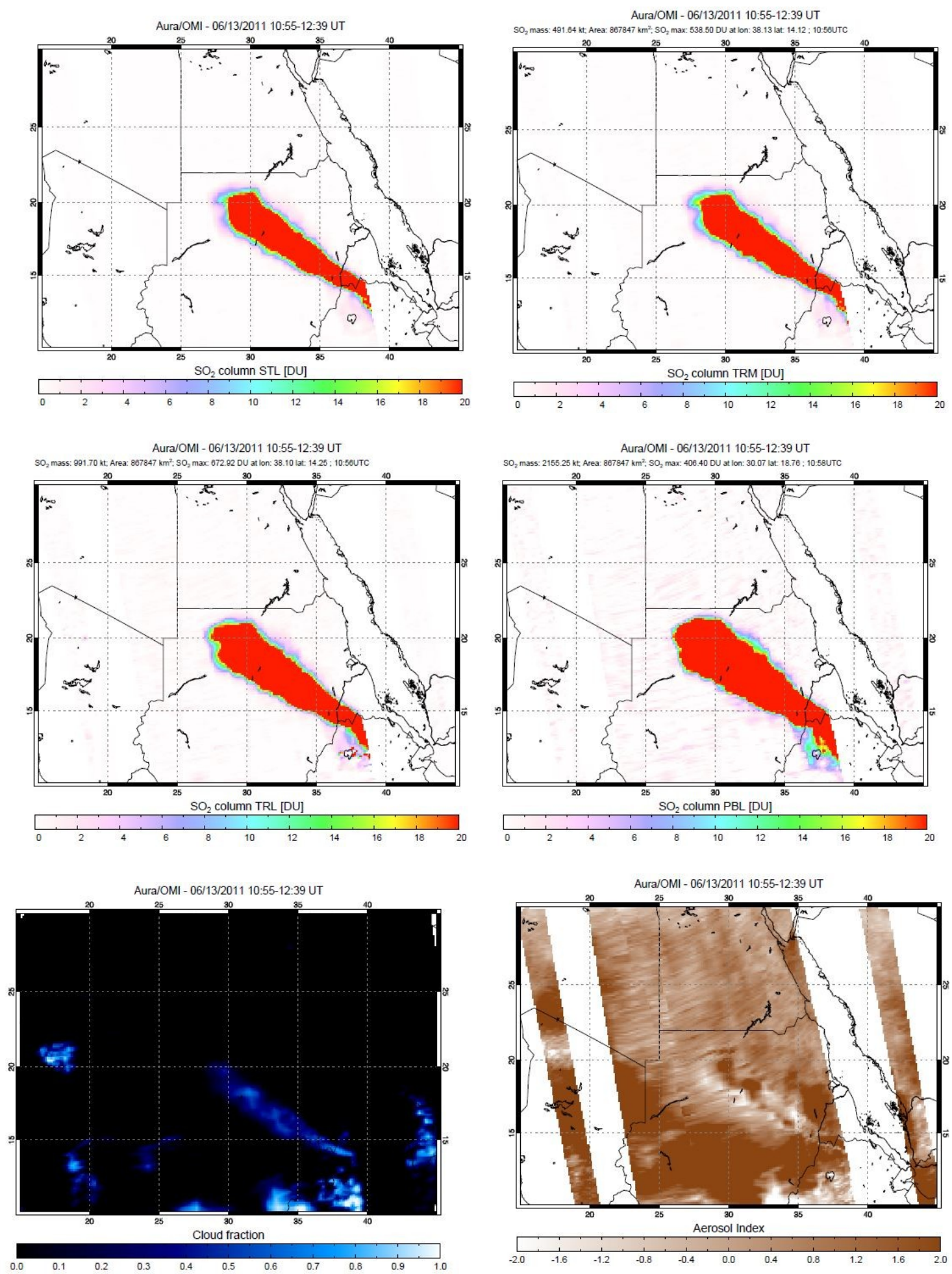

Figure 3: OMIplot output images for 13 June 2011 (top left to bottom right): STL, TRM, TRL, PBL, CF, and AI. Open triangle indicates the location of Nabro. The row anomaly can be clearly seen as an absence of data, particularly in the AI image. 
NOAA HYSPLIT MODEL

Forward trajectories starting at 0000 UTC 13 Jun 11

GDAS Meteorological Data

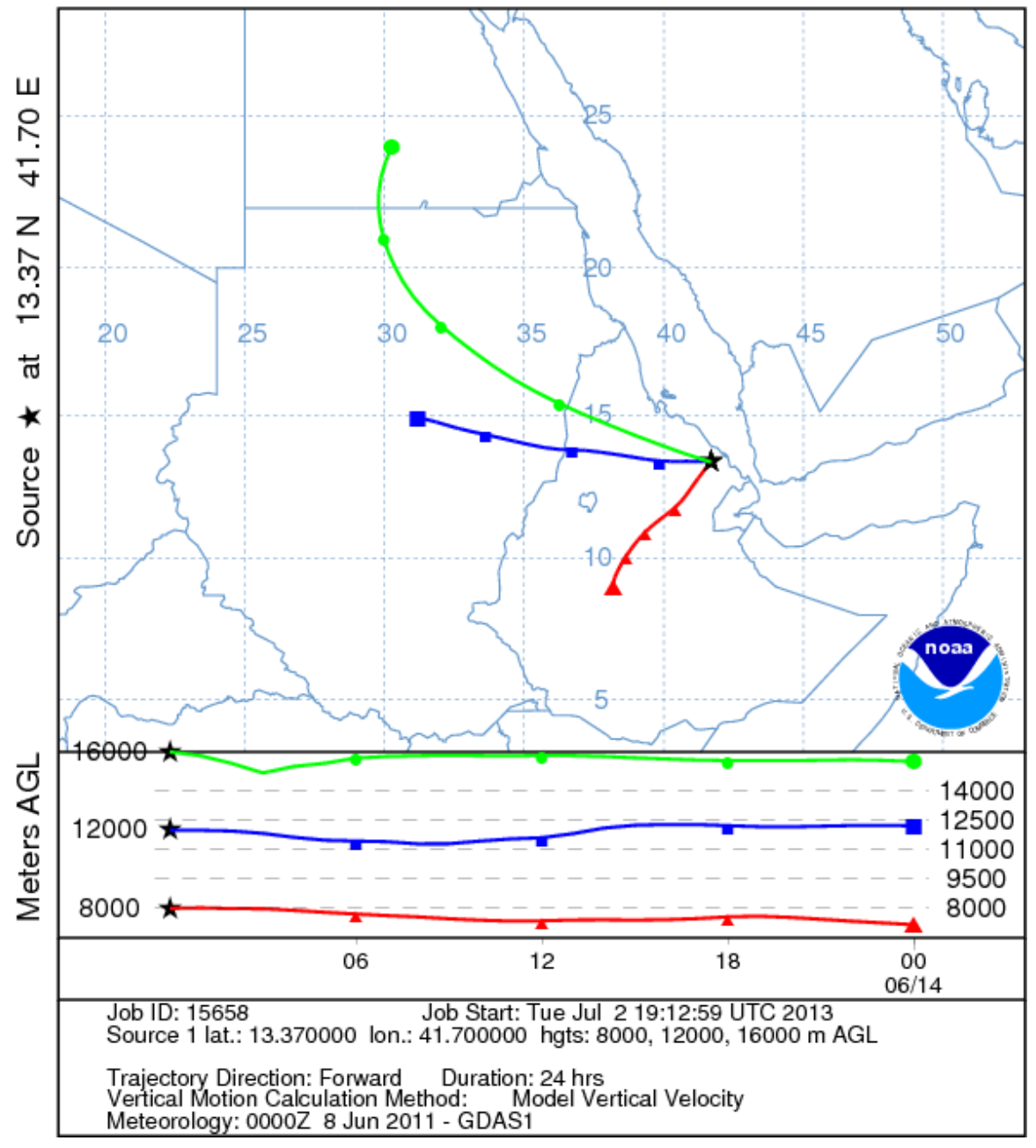

Figure 4: HYSPLIT model for 13 June 2011, showing forward trajectories for three different altitudes: $8 \mathrm{~km}$ (red), $12 \mathrm{~km}$ (blue), and $16 \mathrm{~km}$ (green). 




Figure 5: ALI visible and NIR image, bands 10, 9, 8 (RGB), 29 June 2011. In this image, the lava flow had reached nearly full extent, and the tephra fall is visible as a wide, dark fan with its apex located at the main vent. 




Figure 6: Lava effusion rates as calculated from MODIS Band 32 images, following the method of Harris et al. 1997. Three assumptions for lava surface temperature are shown in blue $\left(100^{\circ} \mathrm{C}\right)$, grey $\left(350{ }^{\circ} \mathrm{C}\right)$, and red $\left(600{ }^{\circ} \mathrm{C}\right)$. Inset shows lava volume emplacement for in terms of percent mass over percent time (all three temperatures plot on top of one another). 


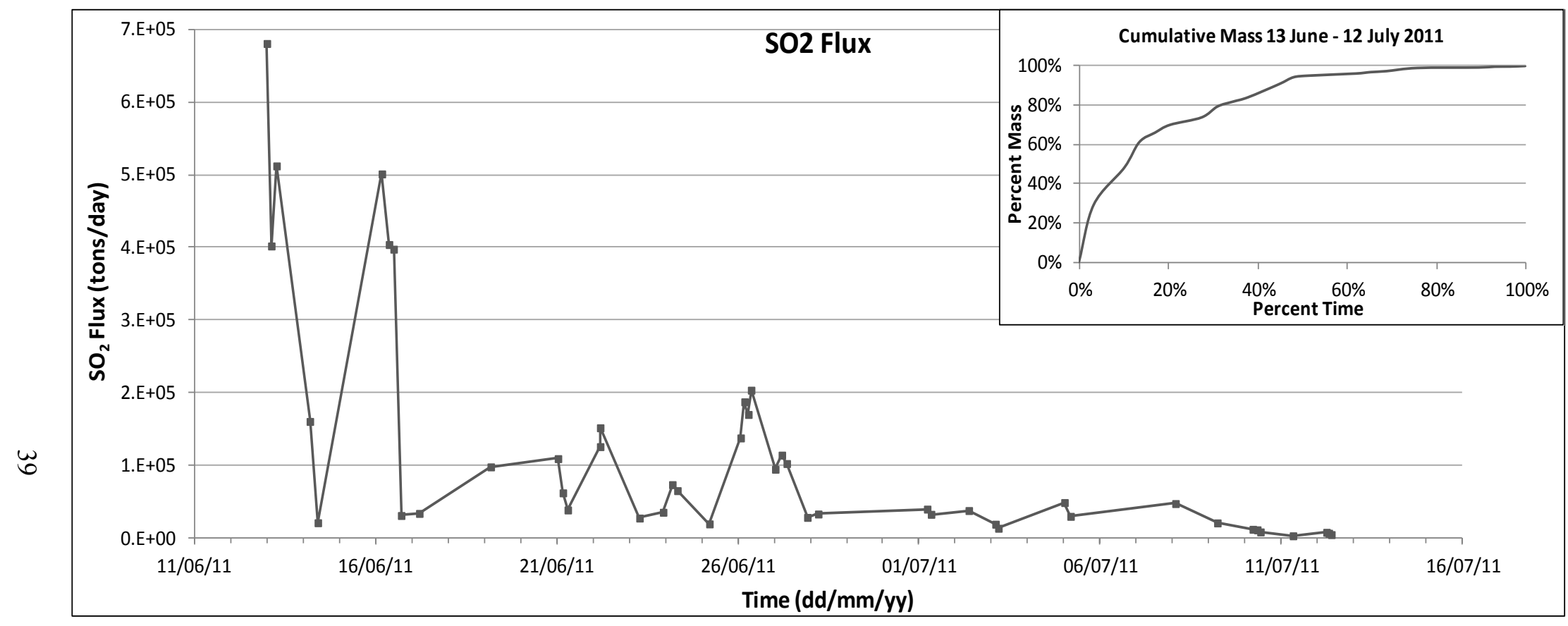

Figure 7: $\mathrm{SO}_{2}$ flux as calculated from OMI data, using OMIPLOT. Inset shows $\mathrm{SO}_{2}$ release in terms of percent mass over percent time. 


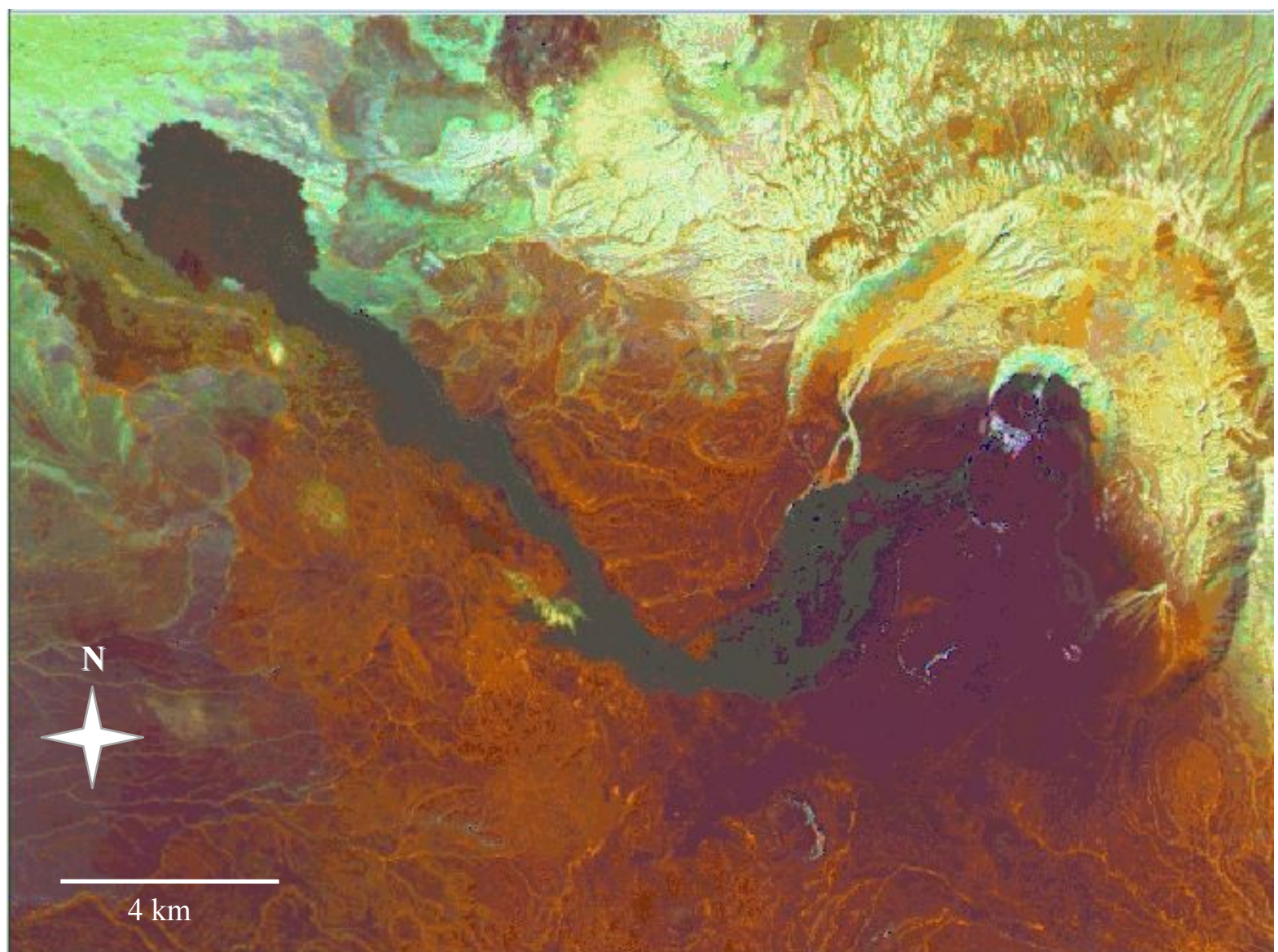

Figure 8: ALI PCA bands 8, 1, 5 (RGB), 16 October 2011. PCA bands 5 and 8 distinguish the lava flow well, appearing in dark grey. PCA band 8 also shows the thick tephra blanket, shown in dark purple. PCA band 1 is best for picking the wide, thin tephra fan, appearing in purple-orange. The full extent of the fan is not shown in this image (see Figure 5). 


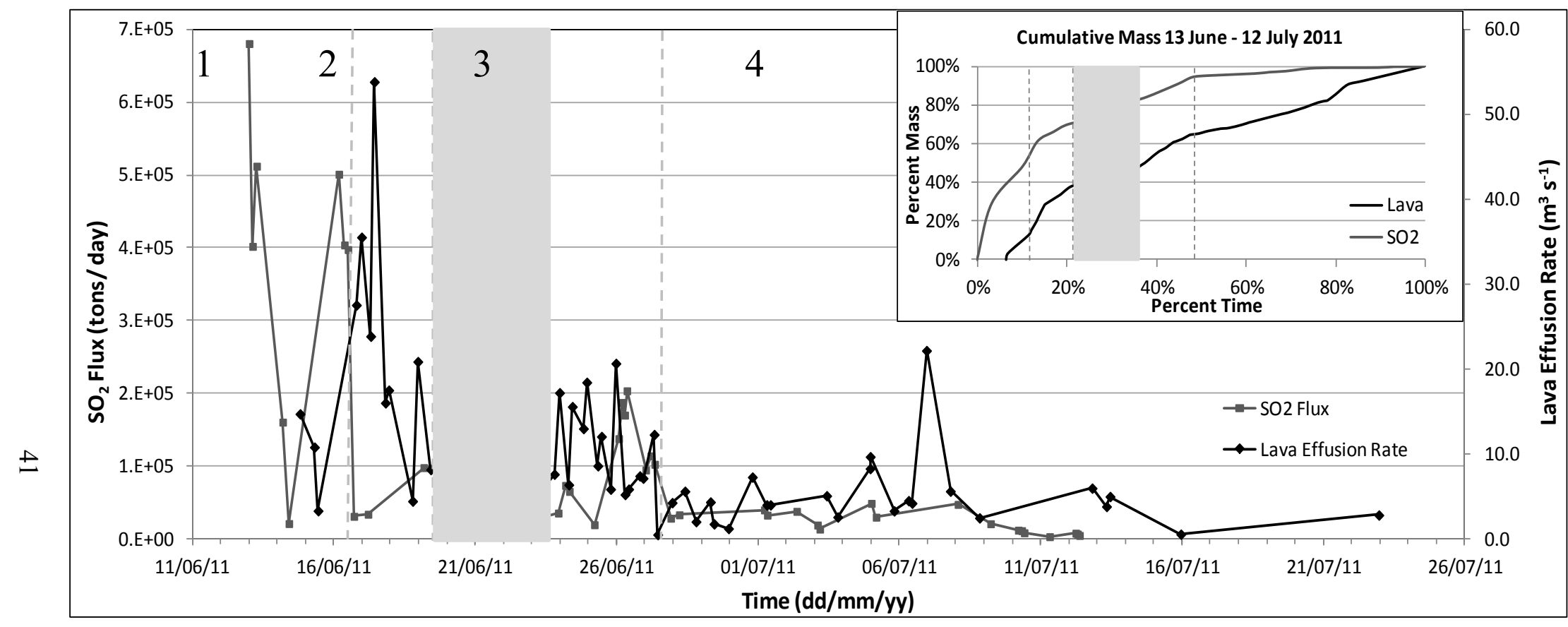

Figure 9: Lava effusion rate (at $350{ }^{\circ} \mathrm{C}$ ) plotted with $\mathrm{SO}_{2}$ flux. Inset shows cumulative mass curves for lava and $\mathrm{SO}_{2}$. The four eruption stages are delineated by grey dashed lines. The shaded rectangle represents a period of heavy cloud cover, which affected retrieval of hot pixels. 


\section{APPENDICES}

\section{Appendix A}

\begin{tabular}{|l|l|}
\hline \multicolumn{2}{|c|}{ MODIS Technical Specfications } \\
\hline Orbit: & $\begin{array}{l}705 \mathrm{~km}, 10: 30 \text { a.m. descending node (Terra) or 1:30 p.m. ascending node } \\
\text { (Aqua), sun-synchronous, near-polar, circular }\end{array}$ \\
\hline Scan Rate: & $20.3 \mathrm{rpm}$, cross track \\
\hline Maximum Scan Angle: & $\pm 55^{\circ}$ \\
\hline Viewing Path: & $10 \mathrm{~km}$ along track at nadir, and $25 \mathrm{~km}$ along track at maximum scan angle \\
\hline Swath Dimensions: & $2330 \mathrm{~km}$ (cross track) by $10 \mathrm{~km}$ (along track at nadir) \\
\hline Telescope: & $17.78 \mathrm{~cm}$ diam. off-axis, afocal (collimated), with intermediate field stop \\
\hline Size: & $1.0 \mathrm{x} 1.6 \times 1.0 \mathrm{~m}$ \\
\hline Powe r: & $162.5 \mathrm{~W}$ (single orbit average) \\
\hline Data Rate: & $10.6 \mathrm{Mbps}$ (peak daytime); 6.1 Mbps (orbital average) \\
\hline Quantization: & 12 bits \\
\hline Spatial Resolution: & $250 \mathrm{~m}$ (bands 1-2) \\
& $500 \mathrm{~m}$ (bands 3-7) \\
& $1000 \mathrm{~m}$ (bands $8-36)$ \\
\hline Design Life: & 6 years \\
\hline
\end{tabular}

\begin{tabular}{|l|l|}
\hline \multicolumn{2}{|c|}{ OMI Technical Specfications } \\
\hline Item & Parameter \\
\hline Visible: & $350-500 \mathrm{~nm}$ \\
\hline UV: & $\mathrm{UV}-1: 270$ to $314 \mathrm{~nm}, \mathrm{UV}-2: 306$ to $380 \mathrm{~nm}$ \\
\hline Spectral resolution: & $1.0-0.45 \mathrm{~nm}$ FWHM \\
\hline Spectral sampling: & $2-3$ for FWHM \\
\hline Telescope FOV: & $114(2600 \mathrm{~km}$ on the ground) \\
\hline IFOV: & $3 \mathrm{~km}$, binned to $13 \times 24 \mathrm{~km}$ \\
\hline Detector: & $\mathrm{CCD}: 780 \times 576$ pixels (spectral $\times$ spatial) \\
\hline Mass: & $65 \mathrm{~kg}$ \\
\hline Duty cycle: & $60 \mathrm{~min}$ (daylight side) \\
\hline Power: & $66 \mathrm{watts}$ \\
\hline Data rate: & $0.8 \mathrm{Mbps}$ (average) \\
\hline
\end{tabular}

Description: The tables above describe specifications for the MODIS and OMI instruments, respectively. 


\section{Appendix B}



\begin{tabular}{|c|c|c|c|c|c|c|c|c|}
\hline \multirow{7}{*}{ JUNE } & RRA & SUN & MON & TUES & WED & THURS & FRI & SAT \\
\hline & \multirow{2}{*}{ WEEK 1} & day & $* \square^{21} 13$ & 14 & \begin{tabular}{ll|}
$*$ & 15 \\
\end{tabular} & $*$ & $\begin{array}{ll}* \square^{21} & 17\end{array}$ & ${ }^{*} \square^{21} 18$ \\
\hline & & night & & $* \square$ & $* \square^{21}$ & $\square$ & $\square$ & $*_{\square}$ \\
\hline & \multirow{2}{*}{ WEEK 2} & 19 & $*_{\square} \quad 20$ & \begin{tabular}{ll|}
$* \square^{21}$ & 21 \\
\end{tabular} & 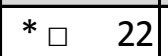 & $* \square^{21} 23$ & 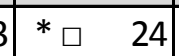 & $\square$ \\
\hline & & $* \square$ & $* \square^{21}$ & $* \square^{21}$ & & $*_{\square}$ & $*_{\square}$ & $* \square$ \\
\hline & \multirow{2}{*}{ WEEK 3} & $*_{\square} \quad 26$ & $\begin{array}{ll}* & 27\end{array}$ & 28 & \begin{tabular}{ll|}
$*$ & 29
\end{tabular} & $\square$ & $\begin{array}{ll}* & * \\
\end{array}$ & $* \square^{21} \quad 2$ \\
\hline & & $* \square$ & & $\square$ & $* \square^{21}$ & $*_{\square}$ & $* \square^{21}$ & $* \square^{21}$ \\
\hline \multirow{8}{*}{ JULY } & \multirow{2}{*}{ WEEK 4} & $*^{*} \square^{21} 3$ & $*^{*} \square^{21} \quad 4$ & 5 & $*_{\square}$ & 7 & $\square^{21}$ & 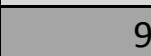 \\
\hline & & $*$ & $* \square^{21}$ & $*$ & & $\square$ & $\square$ & $* \square$ \\
\hline & \multirow{2}{*}{ WEEK 5} & \multirow[t]{2}{*}{10} & $* \square^{21} 11$ & $* \square^{21} \quad 12$ & $*_{\square}$ & \multirow[t]{2}{*}{14} & $\begin{array}{l}4 \\
\square\end{array}$ & 16 \\
\hline & & & $* \square^{21}$ & $\square$ & & & & $* \square$ \\
\hline & \multirow{2}{*}{ WEEK 6} & $\square^{21} \quad 17$ & \multirow[t]{2}{*}{18} & 19 & \multirow[t]{2}{*}{20} & \multirow[t]{2}{*}{21} & $1 * \square^{21} 22$ & 23 \\
\hline & & & & $\square$ & & & & $* \square$ \\
\hline & \multirow{2}{*}{ WEEK 7} & \multirow[t]{2}{*}{24} & \multirow[t]{2}{*}{25} & Legend: & unusable & \multicolumn{3}{|c|}{$\square$ hotspot in both bands } \\
\hline & & & & \multicolumn{2}{|c|}{ * plume and/or cloud } & \multicolumn{3}{|c|}{$\square^{21}$ hotspot in band 21 only } \\
\hline
\end{tabular}

Description: The tables above describe image quality for the study period, for Aqua and Terra MODIS instruments, respectively. 
Appendix B (continued)

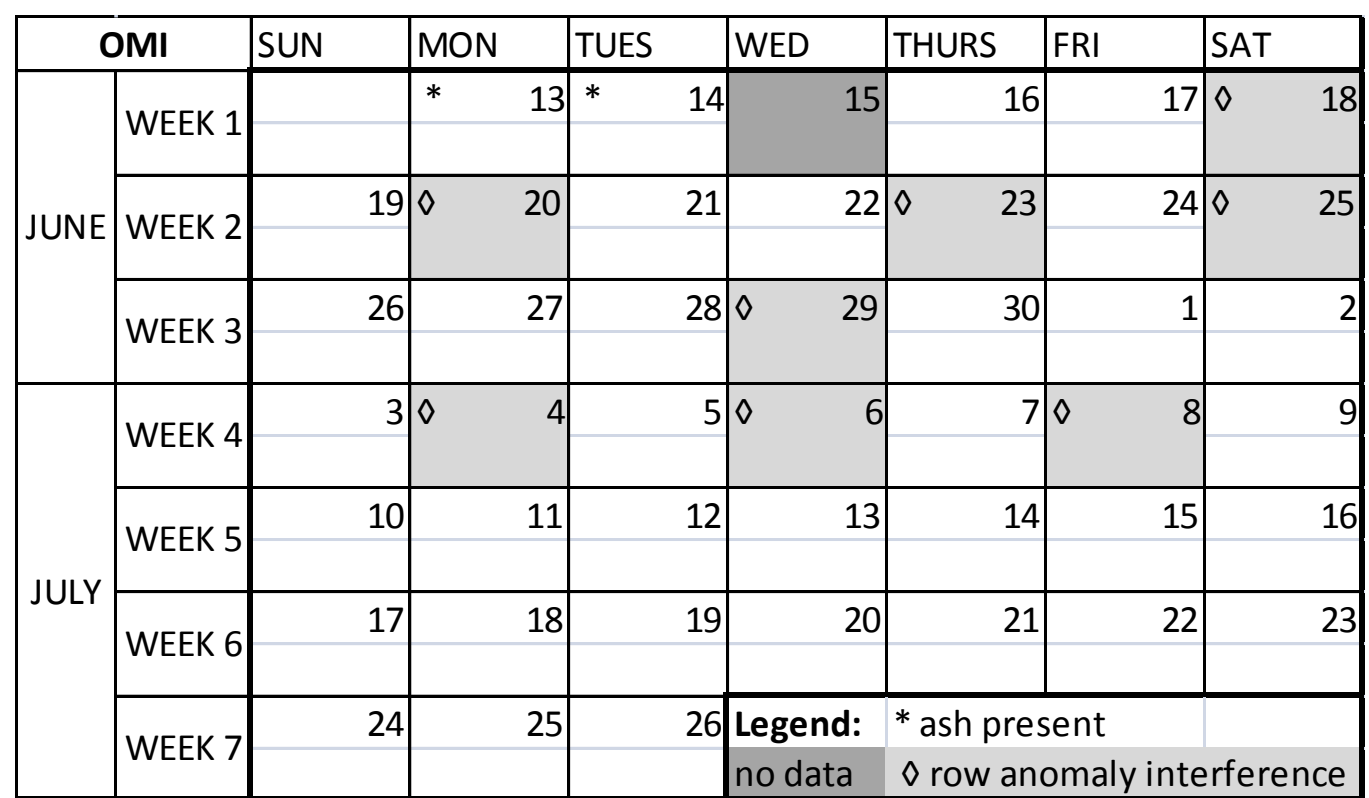

Description: The table above describes OMI data image quality for the study period. 


\section{Appendix C}

\begin{tabular}{|l|r|}
\hline Time (UTC) & Total Mass (KT) \\
\hline 13-Jun-11 10:54 & 365 \\
\hline 14-Jun-11 09:58 & 166 \\
\hline 16-Jun-11 09:46 & 344 \\
\hline 17-Jun-11 09:00 & 235 \\
\hline 18-Jun-11 09:34 & 88 \\
\hline 19-Jun-11 08:49 & 72 \\
\hline 21-Jun-11 10:02 & 69 \\
\hline 22-Jun-11 10:46 & 101 \\
\hline 23-Jun-11 09:53 & 43 \\
\hline 24-Jun-11 10:34 & 42 \\
\hline 26-Jun-11 10:21 & 121 \\
\hline 27-Jun-11 09:34 & 66 \\
\hline 28-Jun-11 10:09 & 15 \\
\hline 01-Jul-11 10:40 & 19 \\
\hline 02-Jul-11 09:48 & 13 \\
\hline 03-Jul-11 10:27 & 9 \\
\hline 05-Jul-11 10:15 & 29 \\
\hline 09-Jul-11 09:52 & 4 \\
\hline 10-Jul-11 10:33 & 8 \\
\hline 11-Jul-11 11:16 & 1 \\
\hline 12-Jul-11 10:21 & 5 \\
\hline 26-Jul-11 10:33 & 7 \\
\hline Total Mass: & $\mathbf{1 8 2 4}$ \\
\hline
\end{tabular}

Description: The table above shows daily $\mathrm{SO}_{2}$ mass values obtained from OMI images over the study period. 